\title{
El proyecto educativo de Soledad Acosta de Samper dirigido a las mujeres en la revista La Mujer, lecturas para las familias (1878- 1881) ${ }^{1}$
}

\section{The educational project of Soledad Acosta de Samper directed to women in the magazine La Mujer, lecturas para las familias (1878-1881)}

\author{
Carolina-Cespedes-Quiroz ${ }^{2}$
}

\begin{abstract}
Resumen
El presente trabajo explora algunas concepciones sobre la educación femenina en la segunda mitad del siglo XIX colombiano, vistas a través de la revista La Mujer. Lecturas para las familias, publicada desde el $1^{\circ}$ de septiembre de 1878 hasta el 15 de mayo de 1881. Fundada, dirigida y en su mayoría redactada por Soledad Acosta de Samper (1833-1913), como se sostendrá en el presente escrito, el objetivo de la autora con la fundación de la revista, fue la creación de una publicación que trascendiera las ideas generalizadas sobre los conocimientos, los intereses y las lecturas que debían permitirse a las mujeres colombianas de la época.
\end{abstract}

Palabras claves: civilización, educación, historia, influencia de las mujeres, moral, religión

\begin{abstract}
The present work explores some conceptualizations on women education in the second half of the XIX century in Colombia, seen throughout the magazine "La Mujer. Lecturas para las familias", published since September 1ro of 1878 until May 15 of 1881. Founded, directed and in its majority written by Soledad Acosta de Samper (1833-1913). as it is going to be sustained in the present written the objective of the female author with the foundation of the magazine, was the creation of a publication that transcended the generalized ideas about the knowledge, the interests and the readings that had to be allowed to the Colombian women of the time.
\end{abstract}

\footnotetext{
${ }^{1}$ Este artículo presenta el resultado del trabajo de grado desarrollado en la Maestría en Estudios Humanísticos de la Universidad EAFIT, dirigido por Patricia Cardona Zuluaga, Doctora en Historia y profesora del Departamento de Humanidades de la misma Universidad.

${ }^{2}$ Socióloga, estudiante de la Maestría en Estudios Humanísticos de la Universidad EAFIT, Colombia. Correo: ccesped3@eafit.edu.co.
} 
Key words: civilization, education, history, influence of women, moral, religion.

\section{Introducción}

Los estudios que se han hecho sobre Soledad Acosta de Samper, han proporcionado luces para reconocer su labor como letrada en el país, particularmente se le ha estudiado de manera más vasta en su faceta de novelista y se le reconoce el papel que tuvo en la segunda mitad del siglo XIX y la primera década del siglo XX sobre todo para la literatura Colombiana. Este es un artículo que desea contribuir al estudio que sobre esta autora se ha realizado, esta vez focalizando el análisis en sus textos facticos, esto es, en sus artículos acerca de la instrucción pública de la mujer y su papel en la sociedad y el énfasis educativo que Acosta de Samper le dio a la historia. Aun así, se reconoce que en los textos posteriores ${ }^{3}$ a la publicación La Mujer, hay una amplia información que de la autora se puede rescatar sin caer en el anacronismo de situarla como feminista, machista o dicotómica.

El lector encontrará que hemos optado por conservar en la transcripción, la ortografía original de la época con el fin de tener una aproximación lo más cercana posible a los textos originales. Por otro lado, la nominación de Soledad Acosta de Samper tenida en cuenta en el presente texto, se realizó con base a su nombre de pila pero de igual manera a su forma de acercarse a los lectores de la revista con su distintivo: La Directora y las iniciales de su nombre, S.A.S, de este modo, veremos una autora que paulatinamente se alejó de sus seudónimos utilizados anteriormente ${ }^{4}$ en la incursión de otras revista y los cuales conservaría para algunos de sus cuentos reeditados para la revista (Aldebarán y Olga).

De la autora de la revista La Mujer, se puede rastrear una amplia biografía ${ }^{5}$, para efectos del presente artículo, es de rescatar que nació en Bogotá el 5 de mayo de 1833, hija del matrimonio del militar, historiador, diplomático y prócer de Colombia, el general Joaquín Acosta y de Carolina

\footnotetext{
${ }^{3}$ La mujer en la sociedad moderna (1895) es un libro completo dedicado al rol de la mujer en la sociedad, este sin lugar a dudas puede mostrar las convicciones, los intereses y los modos de pensar de Acosta de Samper acerca del papel que debería desempeñar la mujer del país.

${ }^{4}$ En la incursión en periódicos anteriores a la publicación de la revista La Mujer, tales como El comercio, El Mosaico y Biblioteca de Señoritas, la autora firmaba sus textos con los seudónimos de: "Aldebarán”, "Bertilda”, "Andina", "Olga" y "Renato"

${ }^{5}$ Sobre la autora Soledad Acosta de Samper ya se encuentra disponible un vasto trabajo biográfico y bibliográfico, sin embargo, es importante mencionar un libro que por su enorme contenido, abarca de manera detallada y holística a Soledad Acosta de Samper, este es: Carolina Álzate y Montserrat Ordoñez, ed., 2005. Soledad Acosta de Samper: Escritura, género y nación en el siglo XIX. Madrid: Iberoamericana Vervuert
} 
Kemble, escocesa, hija de un propietario de una reconocida empresa de fundiciones de cañones en Terry Town y vinculada como su familia a una estricta adhesión al protestantismo cristiano, convicción que no heredará Soledad Acosta, pese a pasar parte de su infancia disciplinada en dicha religión con su abuela en Halifax, Nueva Escocia.

Su recorrido en la esfera literaria la lleva a incursionar en diferentes revistas y periódicos como el caso de Biblioteca para señoritas, que fuera la primera revista dedicada al "bello sexo", una revista que dirigió su esposo en Lima, Perú llamando "El Comercio" y el círculo cultural más importante de la época, llamado El Mosaico, por mencionar algunos ejemplos.

Para la época de publicación de la revista, es importante mencionar el ahínco y fortaleza la llevan a explorar, proponer e ingresar en un ámbito desconocido en el país: la dirección de una revista por una mujer, así La Mujer. Lecturas para las familias, fue una publicación que en sus 1447 páginas, se encuentra una muestra formidable de Soledad Acosta de Samper como ensayística, novelista, consejera, critica, periodista e historiadora, y aunque el 15 de mayo de 1881 termina con la entrega $\mathrm{N}^{\circ} 60$, fue un proyecto que alentó a Acosta de Samper a dirigir 4 revistas más ${ }^{6}$.

\section{Acerca de la especificación y análisis del presente trabajo}

Este estudio es de carácter histórico y hermenéutico, teniendo como referencia una fuente documental que permite analizar cultural y sociológicamente, las condiciones de la educación femenina en Colombia durante la segunda mitad del siglo XIX, para efectos de análisis y especificación del presente trabajo, se realizó una distinción de los artículos encontrados en la revista La Mujer, ubicándolos en dos grandes grupos de géneros escriturales: el primero tuvo que ver con los textos poéticos y narrativos (21 novelas históricas y costumbristas, 16 cuentos, 88 poesías y 5 cuadros de costumbres) (ver tabla 1). Fue, justamente en estas secciones de la revista en donde se pudo evidenciar una mayor incursión de participación de otras mujeres colombianas, tales como la cartagenera Eva Verbel (1856- 1990), la escritora y profesora Caldense Agripina Montes del Valle (1844-1915), caldense y escritora premiada a nivel nacional e internacional por sus obras poeticas. La huilense Waldina Dávila de Ponce (1823-1900) quien fue la autora de la

\footnotetext{
${ }^{6}$ En 1884 hasta 1885, dirige el periódico: La Familia, Lecturas para el Hogar. De 1889 a 1890, El Domingo de la Familia Cristiana. De 1898 a 1899 El Domingo y finalmente Lecturas para el Hogar publicado desde 1905 a 1906
} 
primera novela de Huila llamanda El trabajo y escritoras internacionales como la Italiana Ángela Grassi y la argentina Josefina Pelliza de Sagasta,

En el segundo grupo se ubicaron aquellos escritos periodísticos, históricos, traducciones (ver tabla 3), documentos pedagógicos y las reflexiones de la autora orientadas a enseñar, dirigir e instruir a la mujer colombiana de la época (ver tabla 2). Es, precisamente, alrededor de textos de esta naturaleza donde se ubica la presente investigación.

El texto se divide de seis acápites y unas conclusiones, el primero de ellos tiene que ver con la mención de algunas condiciones generales de la educación para la época de surgimiento de la revista (1878), seguidamente se encuentran las consideraciones que se pensaban necesarias y naturales en la instrucción educativas para las mujeres del país, posteriormente esta fundamentación, permitirá adentrarse contextualmente en las reflexiones de Soledad Acosta de Samper en su revista, con el fin de reconocer el proyecto educativo que la redactora tenía con su publicación, de este modo se explorarán en los acápites 3, 4, 5 y 6 las diferentes secciones que poseen un contenido educativo o instructivo directo hacia las mujeres, de este modo, la presente investigación considera que el papel de la historia (acápite 3), la dicotomía entre el conocimiento intelectual y el deber ser femenino con la que Soledad Acosta de Samper batalló durante toda la publicación de la revista (acápite 4), el papel fundamental de la mujer como influenciadora de la sociedad moderna, primero en el seno familiar y posteriormente en la política (acápite 5) y finalmente el objetivo educativo de la revista para incidir en las condiciones de instrucción pública de la mujer decimonónica (acápite 6), son el constructo que permite reconocer la importancia de esta obra relacionada con los aportes de Soledad Acosta de Samper en materia de educación femenina. Condiciones educativas en el marco de la publicación de la revista "La Mujer.

\section{8- 1881"}

Considerar la interconexión y conjugación que se presentaron entre diversas prácticas socio culturales emprendidas por los mismos ciudadanos a la par de la compresión de las disposiciones legales dispuestas en el marco de las condiciones educativas que se realizaron durante el siglo XIX colombiano y buena parte del XX, resulta además de necesario, categórico, en la medida que demuestra que las ordenanzas y normatividades gubernamentales no se instauraron per se sino que fueron más bien el recipiente o la forma de lo que se deseaba conseguir, soportados por todo un 
acondicionamiento paulatino que no solo se dio en los establecimientos educativos sino también en los hogares, las empresas, las fábricas y también en las relaciones sociales.

Ese conjunto de ideas que se instauraron en la vida colectiva que José Luis Romero señaló como la naturaleza de las mentalidades se ve reflejado en el contexto educativo de una nación que se estaba pensado para el progreso y la modernización, ellas fueron:

Formas concretas de vida; pero junto con ellas, todo ese haz de ideas corrientes, de ideas operativas, que funcionan efectivamente en una sociedad, que no han sido nunca expuestas de manera expresa y sistemática, que no hayan sido nunca ordenadas ni han sido motivo de un tratado, pero que sin embargo nutren el sistema de pensamiento y rigen el sistema de la conducta del grupo social. (Romero, 1987, p. 13)

En su Estudio de la mentalidad burguesa, Romero nos ilustra al respecto de esta categoría, analizando los cambios ocurridos entre el pensamiento cristiano feudal y el pensamiento burgués. El autor indica que, aunque los cambios presentados en la estructura socio económico del mundo son los más visibles y por tanto los más propensos de notoriedad, el sustento de tales cambios son de corte histórico, y con esto la salvedad que la ideología funciona para durar, reproducir y transformar la estructura en cuestión. De este modo se presentó un avance de cambio social en doble vía; el primero dado por las propuestas de los grupos sociales (apertura de escuelas con ciertos perfiles y “especialidades” de enseñanza) y el segundo en evolución a la propia dinámica, la cual no es más que la interiorización o "habitus" en palabras del sociólogo Pierre Bourdieu, de algunas costumbres, ideas, normas y creencias establecidas.

En esta coyuntura social se sitúa el proyecto de Soledad Acosta de Samper, "La Mujer 18781881 " este fue un proyecto no gubernamental (la revista no hizo parte de las publicaciones patrocinadas por el gobierno) como tantos otros emprendidos en la época, el cual tuvo un particular énfasis de incidir en los modos y contenidos que deberían según la directora de la revista, presentarse en la educación de la mujer. Para la fecha, el país (Estados Unidos de Colombia. 18631886) se encontraba en una especial coyuntura dada por las claras confrontaciones entre el gobierno del momento (liberalismo radical) y los grupos políticos en pugna (conservadores e iglesia católica) acerca de los modos como se abordaría la educación para el país. Los encuentros y desencuentros de estos grupos políticos demostraron la convicción de querer incidir en los cambios sociales que fruto de las reformas, emprendería el país. Tanto liberales como 
conservadores coincidieron en el necesario cambio que debía realizarse, con el fin de emprender procesos de modernización, intercambio económico y en general, el mejoramiento de las condiciones de vida, también estaban de acuerdo que para emprender el proyecto de modernización, se debía realizar un trabajo enérgico en los temas de la instrucción pública pues era la única estrategia que podía sostener en el largo alcance las condiciones necesarias para estabilizar la economía del país la cual estaba en agonía debido a los fuertes cambios ocurridos desde el siglo pasado con la separación de la Corona Española y las continuas y devastadoras guerras civiles fruto de la reorganización político administrativa colombiana.

Sin embargo, no hubo acuerdo en los modos de concebir dicha instrucción, de este modo, se presentó una abierta disputa que respondía a las metodologías, teorías pedagógicas y didácticas y contenidos de la educación del momento. El gobierno del período dirigido por una facción radical de los liberales, venía trabajando fuertemente en la puesta en marcha de un proyecto educativo nacional que brindara los parámetros generales de la educación del país. Sus esfuerzos se ven reflejados en proyectos ambiciosos como lo fue el Decreto Orgánico de Instrucción Pública ${ }^{7}$ liderado por la presidencia de Eustorgio Salgar (1870), disposición que organizaba y unificaba el sistema de enseñanza en el país en el marco de una educación laica. Dicha ley estuvo precedida por diversas reformas que proponían entre otras cosas, la separación Iglesia/Estado y una educación basada en el libre credo, para efectos de ilustración se referencia el decreto del 30 de mayo de 1863 que promulgaba la instrucción pública al margen de la autoridad eclesiástica.

El gobierno liberal se basó en el novedoso modelo educativo francés, modelo que entre otras cosas, reglamentaba la implementación de modelos pedagógicos como los de Enrique Pestalozzi, la puesta en marcha de planes, currículos y teorías pedagógicas, además de la ya mencionada, libertad de cultos, todo ello dictaminado en el denominado Decreto Orgánico de Instrucción Pública, ley considerada como hito importante en la consolidación de la educación colombiana:

Los hombres de la generación radical estaban convencidos de que no podía haber democracia con ciudadanos analfabetas y de que el servicio educativo era uno de los deberes del Estado.... Como además estaban convencidos de que la religión era cuestión que concernía sólo al individuo, que dependía de su íntima y personal decisión. (Jaramillo, 1980, p. 3)

\footnotetext{
${ }^{7}$ Decreto Orgánico de Instrucción Pública. (1870) Repositorio de la Universidad Pedagógica Nacional. Recuperado de: http://revistas.pedagogica.edu.co/index.php/RCE/article/view/5024/4110
} 
Sin embargo esta aspiración tropezó con la ya anclada injerencia de la iglesia católica en la esfera educativa, de allí que en algunas regiones, el Decreto no fue tomado estrictamente y la educación religiosa católica predominó durante todo el siglo en algunas regiones del país. Se presentó entonces la confluencia entre el modelo estimado por el gobierno y las acciones sociales llevadas a cabo, sopesadas en la justificación de educar un ciudadano con una moralidad basada en los preceptos religiosos.

El proyecto educativo liberal como era de esperarse, tuvo fuertes detractores insertos en la comunidad católica y en grupos políticos conservadores quienes no percibían que a través de un proyecto educativo laico se podría formar a ciudadanos con una moralidad integra. La fundadora y directora de la revista La Mujer se encuentra en este grupo político, y aunque para la época las mujeres no eran consideradas "sujetos políticos", se verá en el presente artículo las consideraciones morales e intelectuales de esta autora, quien a través de un ejercicio continuado de dos años de producción de la revista, realizó una particular y novedosa propuesta mediadora entre un pensamiento ajeno a los preceptos religiosos (Liberalismo radical) y un pensamiento conservador que situaba a las mujeres en un ámbito doméstico, olvidándose de puntos esenciales que Soledad Acosta de Samper desarrolló ampliamente en su revista como lo fue: la independencia económica de la mujer, la inmersión de las mujeres en la literatura intelectual (o literatura de ramas del conocimiento) y la actuación de la mujer en la esfera política.

\section{Condiciones educativas de la mujer de la mitad del siglo XIX colombiano}

Siguiendo a Aida Martínez, los esfuerzos por concretar una educación oficial para las mujeres y que trascendiera el ámbito del hogar, tradicionalmente dispuesto para el aprendizaje de las letras y la aritmética básica así como de ciertos oficios como los de coser y bordar, se empezó a dar desde finales del siglo XVIII con la construcción del primer colegio para niñas llamado Colegio de la Enseñanza, fundado para el año de 1776 en Santafé de Bogotá ${ }^{8}$, posteriormente y bajo la vicepresidencia de la república de José María Castillo, se decretó a través de la ley del 6 de agosto sobre el establecimiento de escuela de niñas en los conventos religiosos y en la misma fecha, la

\footnotetext{
8 “En el año 1751 la señora María Gertrudis Clemencia de Caycedo y Vélez y su esposo, solicitaron el apoyo de una orden religiosa española llamada Orden de la compañía de María Nuestra Señora, para abrir el que sería el primer colegio para niñas en el país. El 23 de abril de 1783 se abre el primer convento- colegio dedicado a la educación de las mujeres quienes tenían un vínculo familiar con los próceres de la independencia (madres, esposas e hijas)" Extraído de http://www.colegiodelaensenanza.edu.co/QuienesSomos.html (12 de abril de 2018)
} 
ley sobre el establecimiento de escuela de primeras letras para los niños de ambos sexos, la importancia de educar a las niñas a través de una figura moralmente apta como las religiosas y de otro lado, la urgencia de país para la alfabetización y las bases de la educación colombiana. De este modo, una de las leyes en su segundo apartado reza lo siguiente:

Que sin saber leer y escribir los ciudadanos no pueden conocer fundamentalmente las sagradas obligaciones que les imponen la religión y la moral cristiana, como tampoco los derechos y deberes del hombre en sociedad, para ejercer dignamente los primeros y cumplir los últimos con exactitud (Ley 6 agosto de 1821)

Posteriormente y bajo el gobierno del partido liberal, se establecen en la sección tercera del mencionado Decreto Orgánico de Instrucción Pública, las directrices de enseñanza para las niñas, en las cuales se presentan dos artículos que evidencian las especificidades que debía tener la educación para las niñas:

Art. 49. En las escuelas de niñas no se enseñarán sino los principales ramos asignados a las escuelas elementales i superiores, a juicio del director de la Instruccion pública, 1 se distribuirán las horas de trabajo entre la instruccion de tales ramos i la enseñanza de obras de aguja, economía doméstica i otros ejercícios que convengan particularmente a las mujeres.

Art. 50. Son comunes a las escuelas de niñas las disposiciones de este decreto referentes a las demas escuelas, con las variaciones que el Director jeneral de Instruccion pública crea conveniente introducir, teniendo en cuenta las consideraciones especiales que exije la esmerada educacion de este sexo

Es evidente según los anteriores artículos que las formas de concebir la educación de las mujeres se realizó paulatinamente y a través de la impronta diferencial, soportada en el pensamiento de la época que versaba en la naturalización del espacio femenino destinado a la vida familiar, y eventualmente, al ejercicio del magisterio, por lo que básicamente a las mujeres se les enseñaban rudimentos de los diversos saberes como el aprendizaje de la lecto/escritura y aritmética 
básica, mientras se enfatizaba en el aprendizaje de labores "propias de su sexo" como bordar, coser $^{9}$, cantar y los principios de la puericultura.

Sin embargo no se debe olvidar que gran parte de la educación femenina de la época se impartía en el hogar; en las familias con recursos económicos estables como para pagar a un maestro que instruyera a las niñas ${ }^{10}$ se impartía aritmética básica, la lecto escritura y la enseñanza de algún instrumento musical y en los hogares con menos recursos y de bajo acceso a la cultura escrita, se llevaba a cabo una formación dirigida al aprendizaje de oficios "femeninos" (coser, bordar, hilar, cocinar, lavar), que se convertían posteriormente en fuente de sustento económico para la familia y el desenvolvimiento laboral de la mujer. Sin embargo, tanto la educación "escolar, como la educación que se impartía en las familias, se basaron en la moralidad, la religiosidad y la obediencia" (García, 2007, p. 183)

Ahora bien, es importante hacer notar que la fundamentación de la educación para las mujeres colombianas "viró y se resolvió a la luz de las necesidades sociales de establecer una nueva organización del trabajo y la producción, en la cual las mujeres debían participar en unas condiciones específicas." (Pedraza, 2011, p. 75). Para entonces, la educación de las mujeres fue pensada y caracterizada por hombres letrados, quienes prescribieron "las tareas propias del sexo femenino. Parte de este saber consistió en exponer las bases para las relaciones familiares modernas y las tareas de las mujeres en la familia" (Pedraza, 2011, p. 74). Estas disposiciones se evidenciaron en el número significativo de leyes, comunicados, libros para la educación pública, manuales de urbanidad y prensa, utilizados para comunicar la nueva forma de instruir a las mujeres.

Un caso que sirve de ilustración para evidenciar las posturas que estaban en contra de la educación femenina, lo ilustró la revista Biblioteca de señoritas, la cual muestra a un personaje de la época: Ulpiano González ${ }^{11}$ aconsejando a los padres de familia acerca de la formación a sus

\footnotetext{
${ }^{9}$ La revista Historia Critica, revista del departamento de Historia de la Facultad de Humanidades y ciencias sociales de la Universidad de los Andes, realizó en su entrega $N^{\circ} 9$ de 1994 una edición acerca de las labores femeninas en la tradición textil colombiana y su impacto durante los siglos XVIII y XIX

${ }^{10}$ Las familias con recursos económicos considerables, tuvieron la oportunidad de fortalecer la educación de sus hijos a través de la contratación de nodrizas o tutores y la adquisición de libros.

${ }^{11}$ Aunque en el periódico lo nombran con su seudónimo: Juancho Blanco. Fue un ensayista y escritor del siglo XIX
} 
hijas: "resolvemos no proveer de hoy en adelante a la educación de nuestras hijas, porque esto, lejos de proporcionarles felicidad y bienandanza, no hace sino desfalcar su herencia, reproduciendo su desgracia" (Biblioteca de señoritas, 1858, p. 259). Sin embargo, se escucharon voces contrarias de hombres letrados que buscaban una educación intelectual tanto para hombres como para las mujeres: "Reparad que el daño consiste en otra cosa. La falta de ilustración ha sido causa del atraso del país... la educación en el hombre como en la mujer es gran preservativo para la corrupción" (Biblioteca de señoritas, 1858, p. 259).

Este tipo de controversias se presentaron a lo largo del siglo, sin embargo existió un común acuerdo entre todos los estamentos sociales y políticos del país acerca del importante rol de la mujer en el hogar; la economía doméstica pasa a fundamentar las condiciones específicas de desenvolvimiento de la mujer moderna ${ }^{12}$ del país, para ello, el sexo femenino debía instruirse con el ánimo de encarar de la mejor manera posible los deberes de la conducción del hogar. Se concibió, contrario a épocas anteriores que la procreación no era la única función de la mujer, en cambio sí lo fue el seno del hogar, lugar compartido por todas las mujeres: madres, mujeres solteras, religiosas, infecundas o cuidadoras del hogar paterno.

Para autores como Soledad Acosta de Samper, la puesta en marcha de los lineamientos educativos del gobierno liberal, supuso una distancia entre las necesidades sociales y económicas de las clases pobres y las enseñanzas en los establecimientos educativos. La autora hizo notar en la revista su punto de vista respecto a que los saberes no podían alejarse de las instrucciones morales y religiosas y las ciencias en ese sentido, eran innecesarias para las mujeres de escasos recursos, no en términos intelectuales sino y sobre todo prácticos. De este modo, la autora señala que:

Habíase creído entre nosotros que la manera de elevar y dar felicidad a la mujer de las clases pobres, era darla una instrucción intelectual, cultivando en ella ciencias y artes perfectamente inadecuadas para la vida que debe llevar después en el mundo. (Acosta de Samper, 1879, p. 16)

\footnotetext{
${ }^{12}$ Los textos dedicados a la economía doméstica fueron muy importantes en la época ya que facilitaban, orientaba e instruían a las mujeres en esta actividad, al respecto, la autora decimonónica Josefa Acevedo de Gómez (18031861) publica un libro denominado Tratado sobre la economía doméstica para el uso de las madres de familia y de las amas de casa (1848). De igual manera en los manuales de urbanidad colombianos se presentaban por los menos un capítulo dedicado al tema.
} 
Es claro que para Soledad Acosta de Samper, la educación debía diferenciarse entre las clases sociales, sobre todo por lo que representaba económicamente para las "hijas del pueblo" no saberse desenvolver en un oficio o manualidad, aun así juzgaba que todas las mujeres debían desenvolverse fluidamente en las labores manuales e instaba a aquellas de clase social elevada a reforzar ese conocimiento a fin de administrar mejor el hogar: "No se debe permitir que las niñas se dediquen exclusivamente al estudio, aunque sean inclinadas a ello, la mujer es un ser doméstico y es su deber trabajar en obras manuales propias de su sexo" (Acosta de Samper, 1878, p. 152). Dado lo anterior, puede inferirse que Soledad Acosta aún no asimilaba la profesionalización de las mujeres y su dedicación a labores ajenas a las del hogar (en su revista menciona las cantantes, actrices, las botánicas y las médicas). Ninguna actividad femenina debía competir con su "rol natural" como madre, esposa, hermana e hija, dentro de la casa, ir en contravía de ello era, para la época, una situación anti natural y peligrosa para la moralidad femenina, que podría perderse irremediablemente y con ella la vida familiar, ámbito esencialmente asignado.

\section{El papel de la historia en el proyecto educativo de Soledad Acosta de Samper}

Una de las consideraciones del presente escrito, se enmarca en el papel fundamental que Soledad Acosta de Samper le dio a la historia como rama del conocimiento que daría a las mujeres una entrada a la educación intelectual, es decir, la directora de la revista asumía que era a través del conocimiento de las mujeres de las pasada generaciones, que la mujer contemporánea podía tener una injerencia o influencia en su hogar y posteriormente en la vida pública:

Esta es la vedad; sin la ciencia histórica, es decir, sin el conocimiento de lo que hicieron las pasadas generaciones, la mujer no podrá jamas ejercer una influencia provechosa y legitima sobre la sociedad que la rodea. Dios la ha dado una gran misión: la de inspirar y conservar en el corazon humano el sentimiento de la virtud y de la más delicada moral (Acosta de Samper, 1878, p. 2)

Soledad Acosta de Samper realizó una contribución novedosa para la época, ya que si bien, algunos escenarios como el de la literatura, la poesía, el teatro y la novela empezaban a tener una participación paulatinamente por las mujeres, su preocupación en esta publicación se concentraría más por temas de índole político en la medida que era a través del conocimiento de lo ocurrido en pasada generaciones que la mujer colombiana podía tomar parte activa de lo que fue el deseo colectivo del país para la época: la modernidad y el progreso. 
El papel fundamental de la historia en el proyecto educativo de Soledad, se puede evidencia en la sección de Historia, publicada en los 5 tomos de la revista y en las 60 entregas realizadas. Esta sección con la que abre la revista y la que continuamente se ubicaba en las primeras páginas de cada entrega, contó con un único texto llamado: Estudios históricos sobre de la mujer en la civilización, artículos que oscilaban entre 3 y 4 páginas de las 20 o 24 que comprendía cada entrega. En dichos artículos, la directora buscaba señalar la influencia de la mujer a lo largo de la historia de la humanidad.

En todas las historias que hasta ahora se han escrito, sólo vemos la historia de la parte masculina de la humanidad, y en ella se pasa por alto casi siempre la parte á veces importantísima que ha tenido la mujer, directa ó indirectamente, en el progreso ó la ruina de las sociedades (Acosta de Samper, 1878, p. 3)

El texto empieza su narración histórica desde la edad antigua, relatando las proezas de las mujeres hebreas, asirias, escritas, fenicias, griegas, romanas, entre otras, pero también sentando la posición de la directora respecto a las mujeres que fueron una "mala influencia" en la edad antigua, con ello se explicita que, aunque Soledad Acosta de Samper utilizó la historia para impartir conocimiento, todas las publicaciones, aún las traducciones, eran comentadas por ella a través de una escritura de consejo y de orientación hacia la actitud que debía tomar una mujer. Posteriormente, realiza un recuento de la mujer en la edad media, pasando por las mujeres españolas, Galas, de Gran Bretaña y por último, la relación de la construcción de algunos monasterios católicos con las mujeres, esto es; la práctica de beneficencia que defenderá en todos sus artículos.

Otra de las secciones en las que claramente se evidencia el papel de la historia en el proyecto educativo de Soledad Acosta de Samper en la revista, fue la Galería de mujeres virtuosas y notables ${ }^{13}$ publicada en la sección de "Biografías" la cual se entregó en los tomos I, II y III de la revista. La Galería se divide en tres partes, exhibiendo mujeres de la revolución francesa, mujeres de "sociedad" y por último mujeres bienhechoras de la sociedad.

\footnotetext{
${ }^{13}$ Las biografías de esta sección corresponden a: la princesa Isabel de Francia, la Marquesa de Lescure, Adrienne de la Fayyette, la señora Montagu, Rosa Ferrucci, Eugenie de Guerin, Madame Swetchine, Sor Rosalía Rendu, Elizabeth Ann Seton, Magdalena Sofía Barat, Filipina Duchesne y la Marquesa de Barolo
} 
La inversión para esta sección fue considerable, la autora publicaba la Galería cada dos entregas y empleaba entre 6 y 8 páginas para narrar la vida de mujeres que poseían un tipo de perfil que la directora de la revista pensaba era incuestionablemente, a saber; la mujer doméstica, abnegada y católica. En palabras de Soledad Acosta de Samper, la Galería quería resaltar a:

Mujeres contemporáneas enteramente virtuosas, cuyo ejemplo sea digno de seguirse en toda circunstancia de la vida, es quizás un estudio digno de la atención de nuestras lectoras... no hemos admitido sino á mujeres cristianas de todas las naciones, cuyas virtudes sean tan claras como la luz del sol, y cuya reputacion no haya sido manchada con el más leve soplo de maledicencia (Acosta de Samper, 1878, p. 34)

En contraste con Estudios históricos sobre de la mujer en la civilización, en la Galería, la directora deseaba evidenciar la "influencia positiva" que podía ejercer una mujer cristiana, de este modo y tal como lo realizó en sus demás textos facticos publicados en la revista, Soledad Acosta de Samper buscaba alentar a sus lectoras a llevar una vida tan similar a las caracterizadas en la sección, que se permitía inscribir en dichas obras biográficas las cualidades y las garantías de felicidad que trajeron la vida de estas mujeres al inscribirse en la fe católica y en la caridad y por ende, propiciando un marco tradicional educativo que difería del impartido en el momento por el gobierno liberal radical.

Entre la educación diferencial según las clases sociales y la instrucción intelectual para todas las mujeres. Soledad Acosta y su dicotomía entre el conocimiento y el deber ser femenino de la época

Aunque los textos que se mencionarán en el presente acápite podrían ser los que más refuercen el estereotipo de mujer tradicional que se pensaba debía envestir a la mujer colombiana, es importante hacer notar una cuestión que resulta singular en la propuesta educativa de Soledad, puesto que, aunque no se desecha su postura con relación al ámbito "naturalizado" para la mujer, esto es; el hogar, la directora de la revista, no compartió o por lo menos no señaló expresamente en sus textos que la mujer no podía acceder a cierto tipo de literatura debido a una incapacidad de entendimiento o a una postura diferencialista frente a su conyugue.

Un caso que ilustra la contribución de Soledad Acosta de Samper en su publicación a la actividad intelectual se encuentra en la diferencia de pensamiento de la autora no solo con los hombres letrados de la época sino también con algunas mujeres escritoras como el caso de Silveria 
Espinosa de Rendón ${ }^{14}$ (1815- 1886) que al igual que Acosta de Samper, fueron mujeres que participaron en el periodismo de la mitad del siglo XIX y quienes mantuvieron un compromiso con el catolicismo pero que para Espinosa representaba un dogma que no otorgaba las posibilidades educativas que Acosta de Samper deseaba proponer en su proyecto de revista.

Silveria Espinosa pensaba que los libros podían fomentar malos hábitos, alejando a las mujeres de sus dedicaciones domésticas, morales, espirituales y religiosas. La autora explicaba a través del texto Consejos a Angélica: obra dedicada a las niñas cristianas (1887) que: "los malos espíritus se pueden esconder tanto en conversaciones como en libros y periódicos" (Espinosa, 1887, p. 47)

En Acosta de Samper también es evidente la postura de rechazar una educación femenina plenamente intelectual, en su artículo Consejos a las señoritas en su entrada en el mundo, hace un llamado a la vida práctica, sin embargo su postura es menos rígida y como ya se ha expuesto, su ideal tanto en clases pobres como acomodadas es el de mujer culta a través de lecturas morales e históricas.

Soledad Acosta de Samper expresaba al respecto que: "la fuerza moral en la mujer se desarrolla con la educación y la instrucción, es decir, con el acopio de conocimientos útiles" (Acosta de Samper, 1878, p. 4) Para la directora de la revista La Mujer, a diferencia de la autora Silveria Espinosa y algunos escritores masculinos, especialmente en publicaciones religiosas, no se debía considerar una prohibición de todas las lecturas, su declaración acerca del rol que desempeña la mujer en la sociedad le llevaba a tener una fuerte convicción relacionada con el ejercicio racional de la mujer y no meramente práctico ${ }^{15}$.

En sus artículos Consejos a las señoritas en su entrada al mundo señalaba que "no se debe permitir que las niñas se dediquen exclusivamente al estudio, aunque sean inclinadas a ello: la mujer es un ser doméstico y es su deber trabajar en obras manuales propias de su sexo" (Acosta de Samper, 1878, p. 152) sin embargo matiza esta afirmación en sus artículos La Instrucción en la

\footnotetext{
${ }^{14}$ Silveria Espinosa de los Monteros y Dávila, conocida como Silveria Espinosa de Rendón, fue una poetisa y periodista importante del siglo XIX colombiano. Sus obras no son tan extensas como las de Soledad Acosta de Samper pero sin lugar a duda, contribuyó sobre todo en la poesía colombiana a tener un nombre en la esfera internacional, de hecho fue la primera mujer colombiana en ser publicada en Europa.

${ }^{15}$ Siguiendo al escritor francés Louis- Aimé Martin. La autora en la introducción de su libro: La mujer en la sociedad moderna (1895), empieza su texto con las siguientes palabras reveladoras "El porvenir de la sociedad, dice A. Martin, se haya en manos de la mujer, y ella será el agente de la revolución moral que hace tiempo empezó y que aún no ha concluido", 13
} 
mujer de sociedad es una obra traducida y comentada, la directora de la revista extractando un párrafo de la obra "Mujeres sabias y mujeres estudiosas" del Obispo de Orleans, Monseñor Dupanloup $^{16}$, expresa que:

Para habituar á la mujer al trabajo, se necesitara persuadirla de que su educación no acaba á los 18 años, y que su primer vestido de baile, como el diploma de bachiller de los jóvenes, no tiene la virtud de dar conocimiento perfecto de las ciencias (Acosta de Samper, 1879, p. 114)

Con lo anterior, se presenta una claridad importante que fue el balance entre las lecturas y las actividades adjudicadas a las mujeres, de allí que se sostenga que su propuesta fue de algún modo un tránsito entre el discurso hegemónico y una mirada un poco más progresista relacionada con la capacidad de aprehensión y el acceso a las lecturas que debían tener las mujeres de la época.

Consejos a las señoritas en su entrada al mundo fue un artículo publicado en la sección de “Artículos varios” en la entrega \#7 de la revista, en él la directora explicaba a las lectoras jóvenes las condiciones de una "buena" madre de familia, haciendo un énfasis particular en la vida practica y proponiendo un distanciamiento con dos ideales forjados en la sociedad, el primero tiene que ver con los cuentos de hadas, lecturas que para la autora, propiciarían un pensamiento erróneo en las jóvenes ya que destacaban en sus mensajes que "los que se manejan bien obtienen toda especie de recompensas terrenales. Esta errónea educación conduce á la desilusión y á la desgracia” (Acosta de Samper, 1878, p. 153) y otro punto novedoso en Soledad Acosta de Samper; la desestimación que todo matrimonio es bueno per se punto abordado en el mismo artículo con particular interés por la autora.

En el artículo La Instrucción en la mujer de sociedad, publicado en las entregas 16 y 17 de la revista, la directora se permite realizar dos criticas fundamentales, la primera de la mano del Obispo de Orleans, señalando que su obra estaba dedicada a "aquellos hombres que son enemigos de la instrucción en la mujer y que la quieren siempre ignorante" (Acosta de Samper, 1879, p. 87) y aunado a ello, el pensamiento masculino que asume que la mujer es "un ser inferior, cuya existencia no tiene más objeto que el placer y la frivolidad del hombre, dependiente, ante todo, de éste, que es su único dueño...enteramente como si no tuviera ella alma, inteligencia sin libertad

\footnotetext{
${ }^{16}$ Félix Dupanloup (1802- 1878) fue un teólogo y pedagogo activo defensor de la libertad de enseñanza en oposición al laicismo
} 
moral" (Acosta de Samper, 1879, p. 88). La segunda crítica es a la educación nacional que según la directora de la revista, carecía de orden:

Si es difícil y mal dirigida la educación de la mujer en Francia, en donde hay tantos métodos para el caso y recursos infinitos, libros y maestros en todos los ramos del saber humano, ¿qué diremos ¡Dios santo! en Colombia, en donde no hay nada de esto, y ademas tenemos hábitos arraigados de desidia y repugnancia por la instrucción? (Acosta de Samper, 1879, p. 114)

La educación de las hijas de pueblo fue una obra traducida y comentada por Soledad Acosta de Samper, ella conversa con algunos apartados del autor francés Pablo Leroy para apoyar su objetivo con la publicación de la revista que era la defensa de la educación para todas las mujeres, caso que, como ya se ha mencionado, se soporta en una instrucción moral y religiosa, también denunciaba las situaciones de inequidad en el mundo laboral, donde expresaba que la mano de obra femenina era la más baja en todo el mundo y por tanto se presenta un hecho social desigual.

En la entrega \#2 de La educación de las hijas de pueblo, la directora presentó su postura la que no puede leerse a la luz de posturas radicales, es decir, lo suyo no fue ni un proyecto divergente ni un proyecto netamente conservador en la medida que, resalta la educación intelectual pero también ve necesario según las condiciones económicas de las mujeres de escasos recursos, una educación donde prevalezca la instrucción en oficios, a fin de garantizar su sustento y el de su familia:

Pedimos en nombre de la MUJER COLOMBIANA, que se medite seriamente este asunto, y que se procure poner un pronto remedio al erróneo sistema de educación de las clases pobres... [El pueblo] tiene el derecho de exigir de él que no solamente le dé una vida intelectual, abriéndole las fuentes de la ciencia, sino que tiene el DEBER de darle los medios para subsistir honradamente, enseñándole industrias y procurándole ocupación lucrativa, benéfica y meritoria (Acosta de Samper, 1879, p. 19)

Finalmente, Algunos consejos a las señoritas, fueron 8 artículos sobre urbanidad, publicados en una sección del tomo IV llamado del mismo modo, allí y siguiendo la forma escritural de los manuales de urbanidad, la directora le hablaba a las lectoras adolescentes pero también a sus madres acerca del comportamiento en el hogar, la iglesia, las reuniones sociales y la calle.

Los anteriores escritos, pueden agruparse en un segmento que demuestra las claras posiciones políticas de la autora, entendiendo la política como la forma de concebir la sociedad y a sus ciudadanos. En su postura tal como lo señala Azuvia Licón "Se suscribe la idea de que la educación 
femenina implica la educación para ser madres, su postura se distancia de la tradición según la cual las mujeres deben educarse porque serán madres” (Licón Villalpando, 2016, p. 37)

\section{La mujer, una influencia moralizadora en la sociedad moderna}

Es importante hacer notar que Soledad Acosta de Samper, asumió una diferencia tacita entre la participación y el protagonismo en la esfera social, de este modo, entendía que las mujeres podían participar en la política, sin ser protagonistas, entendida en la época como la forma activa, militante y de adherencia a un partido político, reflejada en los comportamientos, la ideología, los valores y los proyectos comunes de una asociación partidista. Su defensa de la mujer ilustrada la llevó a pensar que su relación con el conocimiento, haría de ella una de las más grandes influencias en la sociedad, de hecho en la política, lugar privilegiado para el hombre, tanto desde la acción como desde su conceptualización, Soledad Acosta de Samper, asumió que la mujer también debía tener su rol:

No decimos que tomen parte activa y visible en la política, ni que anden por las calles en tumultos y votando en las urnas, pero si pensamos que la presencia de las mujeres, siquiera como espectadoras inteligentes, en deliberaciones de las cámaras legislativas, sería un gran progreso en nuestro modo de ser”. (Acosta de Samper, 1879, p. 290)

Este ideal es reforzado en su última entrega de la revista, en la que dedica un artículo completo a la actuación de la mujer en la política, La mujer en la política, es un escrito que explica la posición que la mujer debería tomar en asuntos políticos, posición impensable para algunos pensadores de la época pero que se percibe de nuevo en un tono matizado en los escritos de la directora de La Mujer, respondiendo que si bien las mujeres no deben hacer parte del activismo político en calles, manifestaciones o agitaciones públicas, "cuantos bienes no resultan de una influencia sensata y racional de la mujer en la política, influencia pacífica y cuerda que muchas veces produce grandes bienes" (Acosta de Samper, 1881, p. 286). Por tanto, se señala de nuevo que las condiciones diferenciales de la educación de la época debían para Soledad Acosta de Samper, presentarse por condiciones sociales que llevaban a que las mujeres por ejemplo de escasos recursos a desenvolverse en una vida laboral, pero su postulado nunca se dirigió a las capacidades y comprensiones de la mujer en las esferas intelectuales y políticas. 
la mujer... no deberá por supuesto mezclarse en las maquinaciones é intrigas que entre nosotros se llama política, pero ella tiene el deber de comprender lo que quieren y á lo que aspiran los partidos...su deber es instruir desde el hogar a su esposo e hijos. (Acosta de Samper, 1881, p. 286)

\section{La Mujer, el primer proyecto de Soledad Acosta de Samper para incidir en las condiciones de la educación femenina del país.}

A la revista La Mujer, le anteceden 16 años de experiencia que como autora, Soledad Acosta de Samper había tenido ${ }^{17}$. Sus incursiones transcurrieron en la realización de novelas, como corresponsal de prensa en su estadía en Paris y en escritura autobiográfica como es el caso de su Diario Íntimo ${ }^{18}$. Esta experiencia permite ver una autora con una capacidad escritural que fluye entre lo ficcional y no ficcional. En la revista La Mujer, se presenta un objetivo manifiesto: abrir el camino hacia la educación de las mujeres como una vía para mejorar las condiciones familiares y sociales de la Colombia decimonónica.

Tal parece que este proyecto que emprendió Soledad Acosta de Samper en 1878, venía fraguándose desde antes, hecho que puede constatarse no solo en su trabajo como corresponsal en Biblioteca de señoritas sino también en los comentarios que su esposo, José María Samper, declara en la presentación de la primera novela de la autora: Novela y Cuadros de la vida suramericana (1869): “...y ya que su sexo no le permite prestar otro género de servicios a esa patria [Colombia], buscó en la literatura, desde hace más de catorce años, un medio de cooperación y actividad" (Samper, 1869, prologo) Las palabras de José María Samper demuestran que la directora de la revista La Mujer, estaba profundamente comprometida e interesada en participar activamente en la consolidación del progreso de la nación, su papel, como el de muchos letrados de la época fue el de participar a través de la escritura, de las publicaciones y de la actividad pública en el

\footnotetext{
${ }^{17}$ En un comentario de la docente Carolina Alzate, realizado a propósito de una ponencia presentada por Soledad Acosta de Samper en 1892, la autora nos muestra que Soledad Acosta de Samper empieza su ejercicio escritural a la edad de 20 años con la redacción de su Diario íntimo, posteriormente escribe como corresponsal para varios periódicos colombianos en su instancia en París y la incursión en la literatura con su primera obra en 1869: Novelas y cuadros de la vida sur-americana

${ }^{18}$ En el texto: Historia de la vida privada de Philippe Ariès, el autor señala la literatura autógrafa, como uno de los acontecimientos ocurridos en la edad moderna, ella: "da fe de los avances de la alfabetización y del establecimiento de una relación entre lectura, escritura y conocimiento de uno mismo": 11
} 
afianzamiento de una identidad nacional, proyectada en el valor que las letras tuvieron durante todo el siglo XIX.

Para la época de publicación de La Mujer, se percibe una escritora abocada a contribuir en temas educativos, en esta publicación fueron contenidos exclusivos relacionados con el papel de la mujer en la sociedad. Su proyecto de revista posee unos rasgos que llevan a inferir su deseo por incidir en los asuntos relacionados con la consolidación de la educación de la mujer colombiana, proyecto de largo aliento ya que 11 años después de la última publicación (15 de mayo de 1881), Soledad Acosta de Samper, hace una presentación ante el congreso pedagógico reunido en 1892 en Madrid. En el título de su propuesta: Aptitud de la mujer para ejercer todas las profesiones, se observa una autora que va sentando su postura frente a la educación de la mujer, conforme avanzan los procesos sociales: “es preciso que la educación que reciba la mujer sea más adecuada a las necesidades de la época, al grado de civilización de que se disfruta y a las obligaciones que nos impone la patria” (Acosta de Samper, 1892, p. 170). Una mujer que, para Soledad Acosta, tenía la misma capacidad intelectual de los hombres y por ende los mismos derechos educativos: "en mi humilde concepto creo que debería empezarse por probarles que no carecen de inteligencia y que a todas luces son capaces de comprender lo que se les quiera enseñar con la misma claridad que lo comprenden los varones" (Acosta de Samper, 1892, p. 170)

Este hecho, como otros tantos que pueden rastrearse a lo largo de su trayectoria como novelista, periodista e historiadora, lleva a pensar que La Mujer, fue el primer proyecto concreto de la autora en el que declara abiertamente su preocupación por la educación femenina, de allí su importancia, fundamentada en las construcciones de la redactora respecto al tema. Veamos entonces algunos tópicos que pueden rastrearse a lo largo de la revista y que hablan de la postura de Soledad Acosta de Samper frente al deber ser de la educación de la mujer colombiana.

\section{El primero tuvo que ver con el papel de la mujer en el hogar y su vinculación con la religión:} La educación que la autora defendía, cumple con las características exigidas en la época, esto es, una ama de casa y fiel creyente. La mujer debía no solo ser un ser activo en su hogar sino también un ser digno de admirar e imitar, de allí la vinculación creada con la religión católica, aquella que para algunos autores de la época, incluyendo a Acosta de Samper, daría una fuerte formación moral y ética para que las mujeres pudiera afrontar su gran responsabilidad en los hogares. 
Puede decirse que todos los artículos publicados por Soledad Acosta en la revista, cumplen con este parámetro, es decir, en todos ellos se enfatiza en la necesidad de una mujer que sea líder en su hogar (así tenga sirvientes) y una mujer devota. De hecho, para el tercer tomo de la revista, es decir, con 26 números publicados, el Arzobispo de Bogotá Vicente Arbeláez (1822-1884) redactó una carta el 13 de octubre de 1879 (publicada en el número 27 de la revista, noviembre 1 de 1879) donde aprueba las publicaciones de la redactora al presentar la educación para la mujer en dos vías: instrucción y moralización:

Es, pues, el objeto de esta nota, el manifestarle que su periódico merece mi completa aprobacion, y que deseo vehementemente que todas las familias católicas presten su cooperacion al sostenimiento de su periódico, que á la vez que fomenta la buena educacion de la mujer, tiene por objeto conservar la fe y la moral católica en el hogar. (Acosta de Samper, 1879, p. 53)

El segundo tópico puede rastrearse en la conservación por la tradición, es un discurso cauteloso y medido, no es una propuesta divergente ni mucho menos frontal con lo establecido, de hecho, en ninguno de los artículos presentes en los dos años de publicación de la revista, la autora atacó los roles femeninos socialmente establecidos. De hecho, presentó dos críticas a la educación superior impartida a las mujeres, la primera tenía que ver con el recelo que le provocaban profesiones como la botánica, las cuales, según la redactora, exigían a las mujeres salir del ambiente doméstico, lo que repercutiría en el descuido del hogar (padres, hijos y/o esposo). La segunda fue una crítica a la revolución socialista europea, al estar vinculada con la formación laica, de este modo, siguiendo al periódico internacional El Tablet, utilizó en La Mujer, la siguiente cita: "Jóvenes bien educadas parecen que son los agentes favoritos de los comités revolucionarios" (Acosta de Samper, 1879, p. 219). De este modo, se puede percibir que su postura tuvo que ver más con una desconfianza suscitada por todo el accionar político de la época y no por miramientos discriminadores acerca de lo que la mujer tenía capacidad de aprender.

En la revista, se presentan indicios de que Soledad Acosta de Samper batalló con la figura de mujer como objeto sagrado (religiosa) y como objeto doméstico (preocupada solo por los oficios hogareños), son indicios porque la revista no es un proyecto frontal que dirija su atención hacia otro tipo de prácticas por fuera del orden establecido, pero sin lugar a dudas, presenta una 
confluencia de ideas que, por un lado refuerzan la tradición y los roles desempeñados por los hombres y las mujeres y por el otro, introduce novedades acerca del quehacer femenino en su relación con la dependencia económica vinculada a su esposo y las actividades manuales e intelectuales que podía desarrollar la mujer.

En la revista se presenta el deseo de la directora de ampliar el espectro de actividades, pasatiempos, oficios, lecturas y conocimientos de las mujeres. El hogar es el espacio destinado para esta propuesta de Soledad Acosta de Samper, en sus artículos Lo que piensa una mujer de las mujeres, Consejos a las señoritas y Elementos de higiene general, la directora describe una serie de pautas y hábitos que debe adquirir toda mujer, estos van desde el arreglo de la casa hasta actividades de beneficencia como ayudar a un enfermo o instruir a un niño. Para ella, el sedentarismo y la inactividad podría incurrir en una serie de mal prácticas que llevaría a la mujer a ser parasitaria, no funcional y por tanto carente de influencia, la redactora refiere que a las mujeres se les debe: “obligar... á tener siempre ocupación, á que observen un régimen higiénico, sano; y sobre todo, tenerlas alejadas de balcones y ventanas, llevándolas con más frecuencia á hacer ejercicio saludable lejos de caños... evitar conversaciones inútiles, vigilar amistades, sus lecturas" (Acosta de Samper, 1879, p. 251)

De este modo, Soledad Acosta de Samper, buscaba que las mujeres tuvieran un proyecto de vida que fuera acorde a su deber ser femenino dentro de la esfera doméstica. Resulta entonces que el hogar no era una sentencia sino la posibilidad de contribuir a una mejor calidad de vida para las mujeres de la época, promoviendo, en últimas, el mayor énfasis de la redactora con la revista en cuestión: hacer notar la influencia de la mujer en la civilización.

Siguiendo a Zoé Charlotte de Gamond (referenciada en la revista como madama Gatti de Gamond), la directora señaló que: "La educación se divide en dos partes, la educación moral, es decir el desarrollo del alma, y la educación intelectual, es decir, la cultura del espíritu" (Acosta de Samper, 1879, p. 87). A través de las lecturas y el conocimiento, la autora pensaba que la mujer se preparaba para ser la mejor influencia en su familia, por eso aconsejaba que: "la influencia del bello sexo debe pues, ejercitarse para dirigir al hombre por su buen camino, y no hay que dejar olvidar á las mujeres que su misión está en su hogar y al lado de su marido y de sus hijos" (Acosta de Samper, 1879, p. 124). El planteamiento de un rol activo de la mujer en el seno doméstico, demuestra que para la redactora de la revista, la mujer no cumplía una función pasiva, al contrario, 
en el hogar se podía gestar toda una serie de formaciones (morales, intelectuales, ideológicas y políticas) y situaban a la mujer en el papel de dirigir esta influencia. Ya hemos enfatizado que el papel de la mujer no es para la directora, un papel de lo público o del hecho público, pero si lo es desde el pensamiento y desde su contribución en la formación de mentalidades creadas en el seno doméstico.

Otro de los tópicos de este proyecto fue propiciar en las mujeres, condiciones mínimas de educación, precisamente las que ella pudo desarrollar al lado de su padre y posteriormente de su esposo. Su participación en "reuniones científicas en las que se agrupaban los elementos más destacados de las artes y las ciencias. [la llevó a cultivar y mantener] por el resto de su vida, enriqueciendo así en forma constante sus conocimientos y su afán de aprender" (Samper, 1995, p. 135)

Aun, 11 años después de su proyecto educativo en la revista La Mujer, ella pensaba que la mujer no tenía suficiente acceso a la educación como se debería, de allí que se permitiera, en casi todas las esferas, dar a conocer esta limitación, esta vez en un congreso llevado a cabo en Madrid:

En mi humilde concepto creo que debería empezarse por probarles que no carecen de inteligencia y que a todas luces son capaces de comprender lo que se les quiera enseñar con la misma claridad que lo comprenden los varones... debería demostrárseles que si hasta ahora las de raza española son tímidas y apocadas en las cosas que atañen al espíritu, la culpa no es de su inteligencia sino de la insuficiente educación que se les ha dado. (Acosta de Samper, 1892, p. 170)

Hemos visto que Soledad Acosta de Samper intentaba ampliar el espectro de lo que la mujer podía aprender, pero ¿de qué tipo de conocimientos se alejaba? Caracterizar la educación en Acosta de Samper, por lo menos en su proyecto de revista, es señalar que ella se alejaba de las cuestiones de moda y vanidad y aunque algo mencionaba en su sección Revista de Europa, poca trascendencia le dio a estos temas en su publicación, es así como a través del contenido de su revista se puede notar la propuesta de un tipo de educación, un tipo de lecturas y un proyecto de vida especifico en la mujer que iba dirigido al cultivo moral, intelectual y religioso. Ella exponía: 
Otras plumas habrá que se dedicarán a halagar la vanidad de la mujer, á elogiar su belleza ...nosotras procuraremos hablar á su corazon y á su conciencia, recordándola á cada paso que no ha nacido solamente para ser feliz sobre la tierra, sino para realizar muy altos fines de la Providencia. No les diremos á las mujeres que son bellas y fragantes flores, nacidas y creadas tan sólo para adornar el jardín de la existencia. (Acosta de Samper, 1878, prospecto)

Otra de sus distancias es con la literatura romántica que, según la autora, ubica a las mujeres en ideales fútiles que nada tienen que ver con la realidad, hace notar que "la melancolía habitual, los aires de afectado sentimentalismo, las lágrimas y los suspiros, son contrarios a la noble dignidad de una mujer que se respeta" (Acosta de Samper, 1879, p. 251)

En el último tópico, se reconoce la coherencia de su proyecto relacionado con el tipo de artículos publicados en la revista La Mujer: aunque la revista fue un proyecto independiente en un esfuerzo de la directora de la revista, por participar e incidir en los temas de la educación a las mujeres de su época, el seguimiento de su obra completa pero sobre todo, posterior a la revista, demuestra con mayor rigor, la intención de Acosta de Samper por incidir políticamente en las condiciones del género femenino colombiano de la última década del XIX y principios del XX.

Nótese que a lo largo de la revista (ver tablas 1 y 2) no existe por un lado, novelas que refuercen el prototipo de mujer amada, romántica y entregada a la espera de su cónyuge ${ }^{19}$, por lo menos, no se encontrara en los artículos redactados por Soledad, ni notas periodísticas, reflexivas e históricas que propongan una mujer pasiva, entregada por entero a las labores domésticas, a sus hijos y a su esposo.

La apuesta en escena de una Soledad, volcada al periodismo e investigación histórica representa un campo vasto de investigación en el que, sin lugar a dudas, como su proceso como literata, tendrá mucho que decir acerca de sus contribuciones al país, a propósito de la fundamentación de la mujer como sujeto cívico. Sobre este punto, es de reconocer la gran labor realizada por el historiador

\footnotetext{
${ }_{19}$ Un interesantísimo artículo comparativo de tres novelas realizadas en la época, a saber: María (1867) de Jorge Isaacs, Una holandesa en América (1876-1888) de Soledad Acosta de Samper y Manuela (1858-1866) de Eugenio Díaz, muestra los prototipos de mujeres pensadas por estos novelistas. La de Soledad Acosta, una mujer viajera y amante de la historia en la que no se narra ningún hecho romántico. Para ampliar más, ver: a Carolina Alzate con su artículo: Otra amada y otro paisaje para nuestro siglo XIX. Soledad Acosta de Samper y Eugenio Díaz Castro frente a María referencia completa del artículo, falta
} 
Gustavo Otero Muñoz (1894- 1958) quien realizó un artículo en el Boletín de Historia y Antigüedades $^{20}$, un artículo dedicado a nuestra autora en el cual, anexa una amplia bibliografía de Acosta de Samper (ver anexo 3: Bibliografía de Soledad Acosta de Samper) que permite ver las más de 160 publicaciones de la autora en sus diferentes facetas: historiadora, novelista, periodista y traductora entre otras. El fin de anexar el gran trabajo de compilación de Gustavo Otero, responde a una de las necesidades que se evidenció en la presente investigación, ya que Soledad Acosta de Samper al tener una prolífica producción intelectual, esta se encuentra dispersa y de poco acceso, es pues, el trabajo bibliográfico de este autor, un punto de partido que sirvió a esta investigación y por tanto, servirá para futuros investigadores de la obra de Acosta de Samper.

\section{A modo de conclusiones}

Antes de 1878, primer año de publicación de La Mujer, Soledad Acosta de Samper, escribió un número considerable de artículos, cuentos y novelas en los que se puede constatar su afán por instruir a la mujer de un modo particular, esto es, desde un saber intelectual y moral, pero, fue la revista La Mujer, como primera dirección y proyecto editorial seriado emprendido por Acosta de Samper, la que evidencia con mayor rigor su aspiración por producir contenidos y reflexiones acerca de la educación femenina en Colombia. En las 17 secciones y 5 tomos mantendría una intencionalidad explicita; la de instruir a la mujer a través de una disciplina moral construida a través de la literatura y la historia (llama la atención la constancia de la sección de Historia y el posterior trabajo desarrollado por la autora en esta disciplina) y una fundamentación moral y religiosa que le permitiera a la mujer ser una ama de casa influyente para sus familiares, un punto importantísimo ya que muchas veces se la ve como una mujer netamente religiosa pero se pierde de vista el objetivo que Soledad Acosta tenía con el desarrollo de una imagen abocada a la religiosidad y a la moralidad.

Su producción escritural fue una manifestación de la pretensión por construir una mirada que aunada a la figura de la mujer como ama de casa, pudiera renovar el espacio femenino dentro del hogar. Su proyecto se concentra en mostrar los modos que la mujer pudiera ser más activa y dinámica en la esfera doméstica. Es pues, La Mujer, la materialización de un proyecto para la

\footnotetext{
${ }^{20}$ Otero Muñoz, Gustavo. Soledad Acosta de Samper. Boletín de Historia y Antigüedades. Volumen $24, \mathrm{~N}^{\circ} 271$ (mayo 1937): 256- 283
} 
mujer en la vida privada, proyecto que sin lugar a dudas propiciaría una reflexión en lo público y hacia lo público acerca del devenir femenino en Colombia.

La propuesta matizada de Soledad, desarrollada ampliamente en la revista La Mujer, fue también un proyecto político acerca de lo que coyunturalmente en la última década del XIX y principios del XX. La inserción de la mujer en el mundo moderno pasó a ser un tema de suma importancia en la Colombia decimonónica ya que a ella se le otorgó el papel de instruir, moldear y reforzar las conductas morales y el ciudadano que se necesita alcanzar una Colombia moderna en el seno del hogar.

Llama la atención su prudencia para subvertir de algún modo el estereotipo de mujer de la época, ella como tantos letrados de la época, encontraron en la escritura un modo de incidir socialmente en un orden instituido, de este modo, la palabra se convirtió en la reflexión que sirvió para emancipar el pensamiento.

\section{Referencias}

\section{Fuente documental}

Acosta de Samper, Soledad. La mujer. Lecturas para las familias. Revista quincenal redactada exclusivamente por señoras y señoritas. Bogotá: Impreso por Eustacio A. Escovar. Digitalización por Biblioteca Luis Ángel Arango.

\section{Fuentes secundarias}

Acosta, Carmen Elisa, Álzate Carolina y Licón Azuvia, Ed., 2014. LA MUJER (1878 - 1881) De Soledad Acosta de Samper (Periodismo, historia y literatura). Bogotá: Instituto Caro y Cuervo. Acosta, Carmen Elisa y otros, 2003. Medios y nación. Historia de los medios de comunicación en Colombia. Memorias de la VII catedra anual de Historia Ernesto Restrepo Tirado. Bogotá: Ministerio de cultura de Colombia.

Acosta de Samper, Soledad. 1892. Aptitud de la mujer para ejercer todas las profesiones. Memoria presentada en el congreso pedagógico Hispano-Lusitano- Americano reunido en Madrid en 1892. Revista de estudios sociales. $N^{\circ} 38$, (enero 2011): 169- 175. 
Acosta de Samper, Soledad. 1895. La mujer en la sociedad moderna. París: Garnier hermanos, libreros editores.

Red Cultural del Banco de la Republica, "Por primera vez, la mujer tuvo derecho a votar en 1853, 150 años de la Constitución de la Provincia de Vélez Aguilera Peña". CREDENCIAL HISTORIA. $\quad \mathrm{N}^{\circ} \quad 163 . \quad \underline{\text { http://www.banrepcultural.org/biblioteca-virtual/credencial- }}$ historia/numero-163/150-anos-de-la-constitucion-de-velez.

Agudelo Ochoa, Ana María. 2011. "La reflexión decimonónica sobre la escritura de mujeres en $\begin{array}{lll}\text { Colombia”. } & \text { Ciberletras } & \text { vol. }\end{array}$ http://www.lehman.cuny.edu/ciberletras/v25/agudeloochoa.html

Agudelo Ochoa, Ana María y Calle Orozco, Juan Pablo. 2013. Mujeres escritoras en la prensa literaria del siglo XIX. Agenda Cultural, Universidad de Antioquia Mater 201. Páginas pasadas, nuevas historias. (agosto): 1- 3

Agulhon, Maurice. El círculo burgués. La sociabilidad en Francia, 1810- 1848. Buenos Aires: Siglo Veintiuno, 2009

Alarcón Meneses, Luis Alfonso. 2012. libros peligrosos, lecturas impías prácticas y representaciones sociales sobre la lectura en el caribe colombiano 1870-1886. Historia $y$ Espacio vol. 8, No. 38 (septiembre): 121-138.

Alzate, Carolina. 2005. Soledad Acosta de Samper. Escritura, género y nación en el siglo XIX. Madrid: Iberoamericana.

Alzate, Carolina. 2011. Otra amada y otro paisaje para nuestro siglo XIX. Soledad Acosta de Samper y Eugenio Díaz Castro frente a María. Lingüística y literatura N$^{\circ} 59$ (abril): 117-135.

Alzate, Carolina, ed., 2015 Diario Íntimo Soledad Acosta y Diario José María Samper. Bogotá: Publicaciones del Instituto Caro Y Cuervo.

Bermúdez, Suzy. 1993. El bello sexo y la familia durante el siglo XIX en Colombia. Historia crítica $\mathrm{N}^{\circ} 8$ (julio): 34- 51.

Ar Philippe. 1889. Historia de la vida privada. Tomo 3: Del renacimiento a la Ilustración. Taurus. España. 
Aries, Philippe. 1889. Historia de la vida privada. Tomo 6: La comunidad, el Estado y la familia. Taurus. España

Báez Osorio, Miryam. 2002. El surgimiento de las escuelas normales femeninas. Historia de la educación Latinoamericana $\mathrm{N}^{\circ} 4$ (revista anual)

Bourdieu, Pierre. 2000. Sobre el poder simbólico. Intelectuales y poder http://sociologiac.net/biblio/Bourdieu SobrePoderSimbolico.pdf

Cardona Zuluaga, Alba Patricia. 2007. La nación de papel. Textos escolares, política y educación en el marco de la reforma educativa de 1870. Co- herencia Vol. 4, № 6 (enero - junio): 87 113.

Cardona Zuluaga, Alba Patricia. 2014. Retórica, materialidades y prácticas del saber histórico en Colombia durante la segunda mitad del siglo XIX. Co- herencia Vol. 11, N 21 (julio diciembre): $65-95$.

Elias, Norbert. 1998. La civilización de los padres y otros ensayos. Bogotá: Norma.

Elias, Norbert. 2009. El proceso de la civilización. Investigaciones sociogenéticas y psicogenéticas. México: Fondo de Cultura económica.

Espinosa de Rendón, Silveria. 1887. Consejos a Angélica: obra dedicada a las niñas cristianas. Bogotá: Imprenta Silvestre

Eugenio Díaz y otros. 1858- 1859. Biblioteca de señoritas. Imprenta de Ovalles. Bogotá.

Fonnegra Paola, Fonnegra Claudia. 2017. Soledad Acosta de Samper: mujer, formación y virtud. Escritos Vol. 24, № 55 (julio- diciembre): 513- 528.

García Sánchez, Bárbara Yadira. 2007. De la educación doméstica a la educación pública en Colombia. Transiciones de la colonia a la República. Bogotá: Universidad Distrital Francisco José de Caldas.

Gil Medina, Cristina. 2016. La mujer lectora en la "prensa femenina del siglo XIX. Estudio comparativo entre Biblioteca de Señoritas (1858-1859) y La Mujer (1878-1881). Historia y Memoria, No. 13 (julio- diciembre) pp. 151- 183.

Ginzburg, Carlo. 1999. Mitos, Emblemas, Indicios. Morfología e historia. Barcelona: Gedisa. 
González Rey Diana Crucelly. 2005. La educación de las mujeres en Colombia a finales del siglo XIX: Santander y el proyecto educativo de la Regeneración. Historia de la Educación Latinoamericana Vol. 17, No. 24 (revista anual): 243- 258.

Gordillo Restrepo, Andrés. 2003. El mosaico (1858-1872). Nacionalismo, élites y cultura en la segunda mitad del siglo XIX. Frontera de la historia, Instituto Colombiano de Antropología e Historia, Bogotá. ํ 8 (revista anual): 19- 63.

Hayde Gutierrez, Liliana. 2004. A modo de historiografía de la educación colombiana en los primeros años de la independencia. Praxis pedagógica. $\mathrm{N}^{\circ} 15$ (enero- diciembre): 125- 140.

Hernández, Alfonso. 2016. La historia del libro y de la lectura en Colombia. Un balance historiográfico. Información, cultura y sociedad. $\mathrm{N}^{\circ} 34$ (junio): 1- 18.

Jaramillo Uribe, Jaime. 1980. Decreto orgánico. Instrucción pública. Nov 1/1870. Revista Colombiana de educación. Documentos. $\mathrm{N}^{\circ} 5 . \quad$ (revista anual) http://revistas.pedagogica.edu.co/index.php/RCE/article/view/5024/4110

Licón, Villalpando, Azuvia. 2016. "Es cosa muy grave y seria la de criar". Soledad Acosta de Samper frente a los discursos sobre la educación y la maternidad. Meridional Revista chilena de Estudios Latinoamericanos, $\mathrm{N}^{\circ}$ 7, (octubre): 35- 54

Loaiza Cano, Gilberto. 2004. La búsqueda de la autonomía del campo literario El mosaico, Bogotá, 1858- 1872. Boletín Cultural y Bibliográfico Vol. 41, Nº 67 (Primer cuatrimestre): 2- 19

Loaiza Cano, Gilberto. 2007. El maestro de escuela o el ideal liberal de ciudadano en la reforma educativa de 1870. Historia critica $\mathrm{N}^{\circ} 34$ (julio- diciembre): 62- 91.

Londoño V, Patricia. 1990. Las publicaciones periódicas dirigidas a la mujer, 1858-1930: la mujer en los periódicos de América Española. Boletín Cultural y Bibliográfico Vol. 27, No. 23 (segundo cuatrimestre): 3-23

Michaud, Danae. 2013. Soledad Acosta de Samper y la otra historia contada en la mujer (18781881). Ponencia presentada en XVIII congreso de la Asociación de Colombianistas "la mujer en Colombia”. 10 al 13 de julio. Colombia 
Michaud, Danae. 2015. Entre emancipación y abnegación femenina. El discurso paradójico de Soledad Acosta de Samper en Diario íntimo (1853- 1855). Ponencia presentada en XIX congreso de la Asociación de Colombianistas "Colombia, tradiciones y rupturas". 1 al 3 julio. Colombia

Ospina, Joaquín. 1927. Diccionario biográfico y bibliográfico de Colombia. Bogotá, Editorial de Cromos.

Otero Muñoz, Gustavo. 1937. Boletín de Historia y Antigüedades, № 271, Vol. 26 (mayo): 256283

Pedraza, Zandra. 1999. En cuerpo y alma. Colombia: CORCAS Editores LTDA.

Pedraza, Zandra. 2011. La educación de las mujeres: el avance de las formas modernas de feminidad en Colombia. Revista de Estudios Sociales, No. 41 (diciembre): 72- 83.

Rivero Hidalgo, Yanixa Rafaela. 2011. La educación primaria en los Códigos de Instrucción Pública de Venezuela, 1843-1897. Procesos Históricos. Revista de historia y ciencias sociales Vol. 20 (julio- diciembre): 51- 62.

Romero, José Luis (1987) Estudio de la mentalidad burguesa. Alianza Editorial. Buenos Aires Argentina.

Suaza Estrada, Edwin Jader. 2007. Mujer, exclusión y escritura en Colombia. Aproximación a las representaciones y órdenes letrados decimonónicos en la construcción de las naciones latinoamericanas. Estudios Políticos № 50 (revista anual): 100- 114.

Torrejano Vargas, Rodrigo Hernán. (2012) Historia de la educación en Colombia. Un siglo de reformas (1762-1870). Editorial Temis S.A. Bogotá.

Velásquez, Magdala. 1995. Las mujeres en la historia de Colombia. Mujeres, historia y política. Tomo I. Consejería presidencial para la política social. Editorial Presencia, Colombia. 
Tabla 1: Género narrativo y lírico en la revista La Mujer

\begin{tabular}{|c|c|c|c|}
\hline Año & Tomo & Secciones & \# de publicaciones \\
\hline \multirow{3}{*}{1878 a 1879} & \multirow{3}{*}{ I } & Novelas históricas & 6 \\
\hline & & Novelas de costumbres & 2 \\
\hline & & Poesías & 28 \\
\hline \multirow{5}{*}{1879} & \multirow{5}{*}{ II } & Novelas históricas & 2 \\
\hline & & Novelas de costumbres & 2 \\
\hline & & Cuadros de costumbres & 5 \\
\hline & & Cuentos & 4 \\
\hline & & Poesías & 17 \\
\hline \multirow{3}{*}{1879 a 1880} & \multirow{3}{*}{ III } & Cuentos & 8 \\
\hline & & Novelas históricas & 4 \\
\hline & & Poesías & 17 \\
\hline \multirow{3}{*}{1880} & \multirow{3}{*}{ IV } & Novelas históricas & 3 \\
\hline & & Novelas de costumbres & 4 \\
\hline & & Poesías & 15 \\
\hline \multirow{3}{*}{1880 a 1881} & \multirow{3}{*}{ V } & Novelas históricas & 1 \\
\hline & & Novelas de costumbres & 4 \\
\hline & & Poesías & 11 \\
\hline
\end{tabular}


Tabla 2: Artículos analizados en la investigación

\begin{tabular}{|c|c|c|c|}
\hline Sección & Artículo & Entregas & Tomo \\
\hline Historia & $\begin{array}{l}\text { Estudios históricos de la mujer en } \\
\text { la civilización }\end{array}$ & $\begin{array}{l}N^{\circ} 1 \text { al } 12 \\
N^{\circ} 13 \text { al } 24 \\
N^{\circ} 25 \text { al } 36 \\
N^{\circ} 37 \text { al } 48 \\
N^{\circ} 49 \text { al } 60\end{array}$ & $\begin{array}{l}\text { I } \\
\text { II } \\
\text { III } \\
\text { IV } \\
\text { V }\end{array}$ \\
\hline Revistas & Revista de Europa & $\begin{array}{l}N^{\circ} 1 \text { al } 11 \\
N^{\circ} 13 \text { al } 24 \text { (no se hace entrega en } N^{\circ} 17 \text { ) } \\
N^{\circ} 25 \text { al } 36 \text { (no se hace entrega en } N^{\circ} 31 \text { ) } \\
N^{\circ} 37 \text { al } 47 \text { (no se hace entrega en } N^{\circ} 39,42 \text { y } 48 \text { ) } \\
N^{\circ} 49 \text { al } 60 \text { (no se hace entrega en } N^{\circ} 56 \text { ) }\end{array}$ & $\begin{array}{l}\text { I } \\
\text { II } \\
\text { III } \\
\text { IV } \\
\text { V }\end{array}$ \\
\hline Biografías & $\begin{array}{l}\text { Galería de mujeres virtuosas y } \\
\text { notables }\end{array}$ & $\begin{array}{l}\mathrm{N}^{\circ} 2,4,7,8,10 \\
\mathrm{~N}^{\circ} 13,15,19,21,23,24 \\
\mathrm{~N}^{\circ} 26\end{array}$ & $\begin{array}{l}\text { I } \\
\text { II } \\
\text { III }\end{array}$ \\
\hline Ciencias & Elementos de higiene general & $\begin{array}{l}N^{\circ} 12 \\
N^{\circ} 15,17 \text { y } 20\end{array}$ & I \\
\hline \multirow{4}{*}{ Artículos varios } & $\begin{array}{l}\text { Consejos a las señoritas a su } \\
\text { entrada en el mundo }\end{array}$ & $N^{\circ} 7$ & 1 \\
\hline & $\begin{array}{l}\text { La instrucción en la mujer de } \\
\text { sociedad }\end{array}$ & $N^{\circ} 16$, y 17 & II \\
\hline & $\begin{array}{l}\text { La educación de las hijas del } \\
\text { pueblo }\end{array}$ & $N^{\circ} 25,26,27$ & III \\
\hline & La mujer en la política & $N^{\circ} 59-60$ & $\mathrm{~V}$ \\
\hline Moral & $\begin{array}{l}\text { Lo que piensa una mujer de las } \\
\text { mujeres }\end{array}$ & $N^{\circ} 1,3,6,9$ y 11 & $\mathrm{I}$ \\
\hline $\begin{array}{l}\text { Consejos a las } \\
\text { señoritas }\end{array}$ & Algunos consejos a las señoritas & $\mathrm{N}^{\circ} 39,40,42,44,45,46,47,48$ & IV \\
\hline
\end{tabular}

Tabla 3: Obras traducidas por Soledad Acosta de Samper y comentadas en la revista La Mujer (tenidas en cuenta en la investigación)

\begin{tabular}{|l|l|l|l|}
\hline \multicolumn{1}{|c|}{ Articulo } & \multicolumn{1}{c|}{ Autor } & \multicolumn{1}{c|}{ Idioma original } & \multicolumn{1}{c|}{ Entrega en la revista } \\
\hline $\begin{array}{l}\text { Elementos de higiene } \\
\text { general }\end{array}$ & No encontrado & Francés & $\mathrm{N}^{\circ} 12,15,17$ y 20 \\
\hline $\begin{array}{l}\text { La educación de las hijas } \\
\text { del pueblo }\end{array}$ & Pablo Leroy Beaulieu & Francés & $\mathrm{N}^{\circ} 25,26,27$ \\
\hline $\begin{array}{l}\text { Lo que piensa una mujer } \\
\text { de las mujeres }\end{array}$ & Dinah Maria Muloch & Inglés & $\mathrm{N}^{\circ} 1,3,6,9$ y 11 \\
\hline
\end{tabular}




\section{ANEXO 3: BIBLIOGRAFÍA DE SOLEDAD ACOSTA DE SAMPER ${ }^{21}$}

\section{A- CIENCIAS Y RELIGION}

1. La religión y la ciencia. Cuatro capítulos sobre las teorías de Draper, el P. Mir, Flammarion y otros autores, publicados en "La Familia" 1884- 85

2. Breves reflexiones sobre la ciencia antropológica. Cuatro artículos publicados en "lecturas para el hogar" 1905-1906

3. La religión católica explicada. Estudio sobe el libro "Los esplendores de la fe" por el abate Moigno, publicado en "La verdad" año de 1883.

4. Conversaciones y lecturas familiares sobre historia, biografía, critica, literatura, ciencias y conocimientos útiles" Paris, Garnier Hermanos, libreros editores. 1896. 8. 431 paginas. Comprende: lo que es una hacienda en Colombia. Nociones de botánica. Biografías. Las mujeres en la historia de Italia. Cuentos y relaciones. Variedades.

5. "Domingos de la familia cristiana. Evangelios, prácticas y conversaciones sobre religión" Paris, Garnier Hermanos, libreros editores, 1896. 8, 338 paginas.

6. La cristalización de Inglaterra. Estudios y viajes. Cuatro artículos publicados en "Revista la Paz" años 1906- 1907

7. La religión en Francia. "Revista de la Paz" numero 7, año de 1907

\section{B- CRITICA Y ESTUDIOS LITERARIOS}

1. "La Sibila italiana". Romance político por M. Laurent Pichat. Juicio crítico publicado en la "Biblioteca de Señoritas", número 53, año de 1859

2. "El perdón de Ploermel" Ópera cómica en tres actos. Música de Meyerbeer. "Biblioteca de Señoritas" numero 63, año 1859

3. Víctor Hugo. "El Hogar" tomo 1, números 47 y 48, año de 1868

4. Literatura rusa "El Hogar" tomo 2, número 90, año de 1869

5. Cuadros sinópticos de la literatura francesa. "El Mosaico" de 1871

6. Madama Swetchine. "El Mosaico" de 1871, numero 19

7. El "Anuario de la Académica Colombiana". "La Tarde" de 1874, numero 6

8. La vida de aldea en Inglaterra. Artículo sobre el libro "Recuerdos de un desterrado". "Revista Americana" de Lima, año de 1863.

9. La mujer orador. Sobre Madame Clemencia Royer. "Revista Americana" Lima

10. Revista de la bibliografía: libros ingleses y franceses. "Revista Americana" Lima

11. Méjico juzgado por un francés. "Revista Americana" Lima, 1863

12. Novelas inglesas. "La Mujer" tomo IV, número 45, año de 1880

13. Literatas francesas, desde el siglo XIII hasta el fin de siglo XVIII. Siete artículos publicados en el tomo V de "La Mujer", año 1881

14. Escritores modernos españoles: Marcelino Menéndez Pelayo, Pedro Antonio de Alarcón, José María de Pereda. Artículos publicados en "La Familia”, octubre y noviembre de 1885

15. Un nuevo libro de doña Emilia Pardo Bazán: "La revolución y la novela en Rusia". "Correo de las Aldeas" tomo I, 1887; reproducido en "Revista de España" de Madrid.

${ }^{21}$ Este catálogo es una transcripción extraída de: Otero Muñoz, Gustavo. 1937. Boletín de Historias y antigüedades, $N^{\circ} 271$, Vol. 26 (mayo): 256- 283 
16. Diálogos sobre el arte de la pintura. "Lecturas para el hogar" años de 1905 y 1906

17. Rasgos biográficos del autor de Don Quijote. "Lecturas para el hogar" tomo I, año de 1905

18. Una inglesa en Colombia. Sobre el libro "Un año en los Andes o Aventuras de una señora en Bogotá" de Mrs. Rosa Carnegie Williams

19. Doña concepción Arenal de García Carrasco

20. Cuadros sinópticos de la literatura española. "El bien público" números 5 y 8 , año de 1870

21. Cuadro sinópticos de la literatura neogranadina. "El bien público" numero 10, año de 1870

\section{C- ESTUDIOS SOCIALES}

1. Fragmentos y reflexiones: La juventud. La poesía. Ilusiones. Amor y coquetería. Artículos publicados en "El Mosaico", año III, 1864

2. La Monja. "El Mosaico" numero 24, año III, e incluido en el libro "Novelas y cuadros de la vida sudamericana" Gante, 1869

3. Tristeza. "El iris" tomo 4, año de 1867

4. Misión de la mujer. "El Valle" de Cúcuta, número 23, año de 1870

5. Lo que piensa una mujer de las mujeres: La ocupación de la mujer, Independencia personal, El trabajo de la mujer, la madre de familia, la envidia, la maledicencia, la mujer mundana, los caracteres femeninos. Artículos publicados en el tomo 1 de "La Mujer" año de 1878

6. La instrucción en la mujer de sociedad. Id., tomo 2, año de 1879

7. La embriaguez. "La Mujer" tomo 2, número 17 y 18, año de 1879

8. La educación de las hijas del pueblo. Id., tomo 3, números 25 a 27

9. La educación a los veinte años. Cartas a prima Natalia. Obra escrita en francés por A. Rondelet, adaptada al castellano y arreglada para las lectoras colombianas. Publicada en "La Mujer" tomo 31879 y 1880

10. Algunos consejos a las señoritas: La urbanidad en general, urbanidad en el templo, tolerancia en materias religiosas, urbanidad en el interior de la familia, la conducta en las visitas, urbanidad en los bailes, correspondencia epistolar, luto y desgracias. Obra publicada en "La Mujer" tomo 4, 1880

11. Consejos a las madres: I. Primera infancia. II. El niño de ocho meses a un año. III a obediencia. IV El vestido de la primera niñez. "La Mujer" tomo 5, 1881

12. La mujer en la política. Id., tomo 5 , numero 60

13. ¿En qué debe ocuparse la mujer? "La Familia" numero 4, año de 1884

14. Misión de la mujer en la época actual: las hermanitas del jornalero. Las hermanitas de los pobres. Las damas del Calvario. Hospitalidad para el trabajo. El Hospicio de Jóvenes tísicas. Artículos publicados en "La Familia" años de 1884 1885; recogidos luego en el libro "La mujer en la sociedad moderna" Paris 1895

15. Lanzaretos en Europa durante la Edad Media y en la actualidad. "El Domingo" entrega 20, junio de 1899

16. Consejos a las mujeres: La soberanía de la mujer en su casa. La infancia desamparada. La educación de la niñez. Responsabilidad de la madre de familia. Artículos publicados en "Lecturas para el hogar" 1905 y 1906

17. Misión de la escritora en Hispano América. Estudio publicado en "Colombia ilustrada" año de 1889 y reproducido luego en el libro "La mujer en la sociedad moderna” Paris 1895 
18. Influencia de los monasterios cristianos en la civilización. Artículos publicados en el tomo 5 de "La Mujer" numero 57 y 60, año 1881

19. La mujer en Inglaterra. "El Domingo" entrega 19, año de 1899

20. "Biblioteca contemporánea". "La mujer en la sociedad moderna" Parías. Garnier Hermanos, libreros editores. 1895 8, 429 páginas. Libro dividido en seis partes, a saber: La agonía de la sociedad pasada. Cuatro mujeres de la Revolución francesa. Bienhechoras de la sociedad. Mujeres misioneras y moralizadoras. Mujeres doctoras, políticas y artistas. Mujeres literatas en Europa y en los Estados Unidos. Mujeres literatas en la América española y Brasil.

21. "Ensayo sobre la influencia de la mujer en la historia de la humanidad" Este libro quedó listo para la publicación el 20 de julio de 1912, pero la muerte de la autora lo hizo permanecer inédito. Lo forman una serie de estudios históricos sobre la mujer en la civilización, publicados años atrás en "La Mujer" tomos 1 a 5 con algunos otros de los que ya se enumeraron anteriormente y una galería de mujeres heroicas: Magdalena de Vecheres, Arnalda de Rocas y doña Mariana Pineda. Esta obra y la de "La Mujer en la sociedad moderna" son fundamentales para conocer el movimiento feminista a través de la historia, desde los pueblos de la civilización de Oriente hasta las modernas culturas europeas

\section{D- HISTORIA}

1. "Biografía del general Joaquín Paris" Obra premiada en el concurso histórico literario abierto en Bogotá, con ocasión del primer centenario del Libertador Simón Bolívar. Bogotá. Imprenta de Medardo Rivas. 1883. 4, 45 páginas. También se publicó este trabajo en las entregas del "Repertorio Colombiano" correspondientes a noviembre y diciembre de 1883

2. "Biografías de hombres ilustres o notables", relativas a la época del descubrimiento, conquista y colonización de la parte de América denominada actualmente Estados Unidos de Colombia. Obra destinada al servicio de la instrucción pública. 1883. Bogotá, Imprenta de "La Luz". 4, XVI y 447 páginas. Comprende: Los descubridores. Conquistadores. Misioneros y conquistadores subalternos. Los baquianos. Perros de la conquista.

3. "Memorias presentadas en congresos internacionales que se reunieron es España durante las fiestas del IV centenario del descubrimiento de América en 1892" Chartres. Imprenta de Durand. 1893. 4, 91 páginas. Contiene las siguientes monografías: "Los aborígenes que poblaron los territorios que hoy forman la Republica de Colombia, en la época del descubrimiento de América. Memoria sobre el establecimiento de hebreos en el Departamento de Antioquia. Aptitud de la mujer para ejercer todas las profesiones y Periodismo en Hispano América"

4. "Descripciones de Istmo de Panamá en el siglo XVI" "Los contemporáneos de Cristóbal Colón" "las esposas de los conquistadores". Estudios publicados en los tomos 1, 2 y 3 de la revista "El Centenario" de Madrid, dirigida por don Juan Valera, en el año de 1892

5. "Los Juanes del siglo XIV". Estudio publicado en los números 58 a 60 de "La Mujer" abril y mayo de 1881

6. "Historia del primer asno de la Conquista" "El pasatiempo" de Bogotá, números 31 y 32. Tomo 1, mayo de 1878

7. “Historia de la viruela” Breves apuntaciones. "La Luz" número 50, agosto de 1881 
8. "La mujer española en Santafé de Bogotá" "Revista Literaria” tomo 1, año de 1890 y "Lecturas para el hogar" numero 9, noviembre de 1905, bajo el título "Las santafereñas de la época de la Colonia"

9. "Biografías contemporáneas", publicadas en "La Familia", año de 1884. I. Andrés Noguera. II. El general José Sardá. III. Don Alejandro Vélez reproducida en el BOLETIN DE HISTORIA Y ANTIGUEDADES, tomo 2. IV. El general Manuel Serviez

10. BIOGRAFIA DEL GENERAL JOAQUIN ACOSTA, "prócer de la independencia, historiador, geógrafo, hombre científico y filántropo". Apareció primeramente este magnífico estudio en las páginas dela revista "El Domingo" tomos 1 y 2 por los años de 1898 y 1899, pero allí quedó inconcluso, Ilegando solamente hasta terminar el capítulo XII de la segunda parte, que estudia acontecimientos del año de 1827. La autora preparaba una edición en volumen separado, por la misma época, la cual solo alcanzó al final de la primera parte, con un total de 80 páginas en 4, que llevan en su portada la referencia: "Bogotá- Colombia. Tipografía de La Luz 1898", edición que, sin duda, fue suspendida por las circunstancias anormales del país, en vísperas de la guerra de los mil días. Tres años después apareció el libro definitivo, de 502 páginas en 4, con una carta-prólogo del doctor Manuel Uribe Ángel, editado en Bogotá por la Librería Colombiana de Camacho Roldán \& Tamayo, 1901

11. "Biografías de hombres ilustres de Hispano América", publicadas en "Lecturas para el hogar" a saber: I. El general Miranda. Tomo I, pagina 305. II. Atahualpa, el último de los Incas. Tomo I, página 369. III. Los Pizarros y los Almagros. Tomo II, página 26. IV. El general Francisco de P. Santander. Tomo II, página 69. V. El general José A. Páez. Tomo II, página 281. VI. El general Manuel Belgrano. Tomo II, página 338. VII. Don José Miguel Sanz, el Licurgo venezolano. Tomo II, página 340

12. "Tres sabios sudamericanos": Juan Ignacio Molina, fray Vicente Solano y Francisco José de Caldas. "Lecturas para el hogar", tomo II, página 153.

13. "Dos hombres públicos colombianos": El general Tomás C. de Mosquera y el doctor Rafael Núñez. "Lecturas para el hogar" tomo 2, páginas 18¿97 y 209

14. "Descubrimientos de América" "Lecturas para el hogar" tomo 1, página 116

15. Las mujeres de la Gran Colombia en la época de la Independencia. "Lecturas para el hogar" tomo I, página 129

16. Relaciones de los Estados Unidos con las naciones vecinas"

17. "Catecismo de Historia de Colombia". Publicación del Ministerio de Instrucción Pública. Dona por la autora al Gobierno de Colombia para la enseñanza en las escuelas primarias del país. Bogotá. Imprenta Nacional. 1905, 8, 120 páginas.

18. "Lecciones de Historia de Colombia" Edición oficial del Ministerio de Instrucción Pública. Bogotá. Imprenta Nacional. 1908. 4, 402 páginas y X de índice.

19. "Biblioteca Historica”. Epoca de la Independencia. Bogotá. Imprenta Moderna. 1909, 1910. Consta esta obra de dos tomos, y cada uno de doce cuadernos, con un total de X, 376 y 382 páginas en 8 menor. Contiene los siguientes estudios: "LOS PRECURSORES": I. el general Antonio Nariño. II. El general francisco Miranda. "GENERALES ILUSTRES": Antonio José de Sucre. El asesinato del mariscal Sucre. La suerte de los asesinos del gran marcial Sucre. "EL LIBERTADOR SIMON BOLIVAR": Primera parte: 1783-1821. Segunda parte: 1821-1830. Tercera parte: 1830. "LA CONSPIRACIÓN DEL 25 DE SEPTIEMBRE DE 1828" “PRELIMINARES DE LA GUERRA DE A INDEPENDENCIA EN COLOMBIA" 8 capítulos. "LA REVOLUCIÓN DE LA 
INDEPENDENCIA EN LAS COLONIAS ESPAÑOLAS DE AMERICA": El 20 de julio de 1810 en Santafé de Bogotá. Las mujeres de la época de la Independencia. "HEROES FRANCESES DE NEUSTRA GUERRA MAGNA": I. el general Manuel de Serviez. II. Pedro Labatut. III. Luis Fernando de Chatillon. IV. Caros Castelli. V Perú de la Croix. VI. Alejandro Petion. "EL GENERAL JOSE SARDA Y OTROS ESPAÑOLES PATRIOTAS": Cortés Campomanes, José M Moledo, Francismo Aguilar, Buch, Jaló, Villapol, Campo Elías, Antonio Pallares, José Mires. "EL GENERAL JOAQUIN PARIS. EL GENERAL JOAQUIN ACOSTA" extracto de la biografía extensa, publicado ya desde años antes en el número 105 del "Papel Periódico llustrado". "PRESIDENTES DE LA REPUBLICA DE LA NUEVA GRANADA": I. Francisco de Paula Santander. II. José Ignacio de Márquez. III. Pedro Alcántara Herrán. IV. Tomás C. de Mosquera.

20. MONOGRAFIAS HISTORIALES: I. El Cabo de la Vela. II. La conquista de los pijaos. Últimos estudios históricos de la señora Acosta, publicados en los tomos 6 y 7 de la "Revista del Colegio del Rosario", años de 1910 y 1911

\section{E- NARRACIONES BREVES}

1. La perla del Valle. Cuento. El mosaico. Año III. 1864. Reproducido en "El Céfiro" de Panamá, año de 1866 y en el libro de la autora "Novelas y cuadros de la vida sudamericana" Gante, 1869.

2. Luz y sombra. Cuadros de la vida de una coqueta. "El iris" de Bogotá. Tomo 1 año de 1866. Reproducida en el mismo libro y en el tomo II de "La Biblioteca Aldeana de Colombia". Selección Samper Ortega. Bogotá 1936.

3. Ilusión y realidad. Recuerdos de Santafé. "El Hogar" tomo 2 año 1866. Reproducido por el libro ya citado y en "La Guirnalda Literaria", volumen editado en Guayaquil. 1870.

4. Mi madrina. Recuerdos de Santafé. "El Hogar" tomo 1 año de 1868. Reproducido por "El Álbum de los pobres", impreso en Bogotá, 1868 y en el libro de Nepomuceno J. Navarro titulado "lirios y Azucenas" Socorro, 1871. También figura como obra editada en Gante por la autora.

5. Una hora en mi ventana. "El hogar", tomo 1, año de 1868. "El Bien público" numero 40, 1870 y "La Mujer", tomo 2 año de 1879

6. Mercedes "El Hogar" tomo I año 1868

7. Un corazón de la madre "El Hogar" tomo 2 año de 1869

8. Abnegación "El Hogar" tomo 2 año de 1869

9. Un crimen "El Hogar" tomo 2 año de 1869. Reproducido en el libro de la autora "Novelas y cuadros de la vida sudamericana"

10. La juventud del día "El Hogar" tomo 2 de 1869 y "El Bien Público" numero 14 de 1870

11. La violeta "El Hogar" tomo 2 año de 1869

12. Federico. Recuerdos de mi infancia "El Bien Público" número 9, agosto de 1870

13. Una venganza. Cuadros y costumbres populares. "El Bien Público" de Bogotá, números 30 a 34, septiembre de 1870

14. Una pesadilla "La Caridad" tomo VIII, año de 1872 y "La Mujer" tomo 1 año de 1878

15. La vida de dos mujeres. Cuadro íntimo. "La Tarde" de Bogotá, numero 10 a 13, año de 1874

16. Una catástrofe. cuento nacional "La Unión Colombiana" numero 1 al 9 año de 1875 y "La Mujer" tomo 5 año de 1881 
17. La cruz de la vida. Fantasía. "El Pasatiempo" tomo 1 año de 1877, "La Mujer" tomo 3 de 1880, "Colombia Ilustrada". Un fragmento 1889 y "Lecturas para el hogar" 1905

18. Francisco Martín. Episodio de la época de la conquista. "El Pasatiempo" tomo 1 año de 1878

19. Historia del primer asno de la Conquista. "El Pasatiempo" tomo 1 año de 1878

20. Sebastián Cabot "La Mujer" tomo 1 año de 1878

21. Los primeros mártires "La Mujer" tomo 1 año de 1878

22. El fuerte desamparado "La Mujer" tomo 1 año de 1878

23. El cacique Chucurumay "La Mujer" tomo 1 año de 1878

24. Historia de una flamenca. "El Deber" numero 47 a 51, año de 1879 y luego en "La Mujer" tomo 4 de 1880 bajo el título de "Una flamenca del siglo XVI"

25. Mis sobrinos y yo "El Bien Público" numero 12 y 13, 1870 y en "La Mujer" tomo 2 de 1879

26. Mis sobrinos en la iglesia. "La Mujer" tomo 2, 1879

27. ¿se podrá engañar al diablo? Leyenda fantástica. "La Mujer" tomo 2 año de 1879

28. La india de Juan Fernández. Cuadro histórico novelesco "La Mujer" tomo 4 año de 1880

29. Una mujer modelo. Fragmento de una novela de costumbres "La Luz" numero 70, octubre de 1881

30. La esposa del contador Urbina. "La Luz", número 93, enero de 1882

31. El ángel de doña Juana. "La Luz", número 97, enero de 1882

32. Una aparición en 1651. "El Papel Periódico Ilustrado" tomo 1, 1882. Reproducida en "Registro Municipal" de Bogotá año de 1933

33. Tipos populares: la señora de la tienda. 1833

34. Hernán Cortés. Relación novelesca publicada en "La Familia” año de 1884

35. El esposo de Carlota "La Familia" año de 1884

36. Bartolomé Sánchez. Cuadro de la época colonial. 1885

37. La nariz de Melchor Vásquez. Crónica del siglo XVI, 1885

38. Un capricho inexplicable. "La Nación” de Bogotá, 1885

39. Traición y castigo. Leyenda histórica "Revista Literaria" tomo 1 año de 1890 y "Biblioteca Histórica" número 2 página 42

40. Amor de la madre, que todo lo demás es aire "Revista nacional" 1897

41. El nacimiento de Cristóbal Colón. Cuadro histórico fantástico "El Domingo" tomo 1 año de 1898

42. Más vale muerto que culpable. "El Domingo" tomo 1 año 1898

43. Consecuencias de una contradanza. "El Domingo" tomo 1 año 1898

44. El diamante de los Estuardos. "El Domingo" tomo 1 año 1898

45. El guante de Conradino. "El Domingo" tomo 1 año 1898

46. Bogotá en el año 2000. Refundición del artículo "Una pesadilla" "Lecturas para el hogar" tomo I año de 1905

47. Percances de un té. "Lecturas para el hogar" tomo 1, 1905

48. Don Renato y sus sobrinos. Refundición y ampliación del artículo "Mis sobrinos y yo" "Lecturas para el hogar" tomo 2, años 1905 y 1906

\section{F- NOVELAS}

1. "Dolores" cuadros de la vida de una mujer. Publicada como folletín de "El Mensajero" año de 1867. Recogida en el libro "Novelas y cuadros de la vida sudamericana" Gante, 1869 y 
traducida al inglés bajo el título de "Dolores" the story of a leper. Translated from the spanish. Nueva York

2. "Teresa la limeña" páginas de la vida de una peruana. Publicada en el folletín de "La Prensa" de Bogotá, año de 1868 y recogida en el libro citado, Gante, 1869

3. "El corazón de la mujer" Ensayo psicológico, publicado en el volumen "Novelas y cuadros de la vida sudamericana" y reimpreso después en Curazao. Imprenta la Librería de A.

Berthencourt e Hijos, editores, 1887, 124 páginas.

4. “José Antonio Galán". Episodio de la guerra de los Comuneros. Publicada en el folletín "El Bien Público", número 1 al 7 julio de 1970. Años después apareció el libro "Episodios novelescos de la historia Patria" "La insurrección de los Comuneros" 1887. Bogotá imprenta de "La Luz" primera parte. José Antonio Galán. Segunda parte Juan Francisco Berbeo. VII, 191 páginas y 1 de índice.

5. "Laura" novela psicológica. Publicada en el folletín de "El Bien Público", numero 34 a 40, noviembre y diciembre de 1870

6. “Constancia" Publicada en el folletín de "El Bien Público", números 76 a 90, abril a junio de 1871

7. "La holandesa en América" Novela psicológica y de costumbre. Publicada en el folletín de "La Ley" número 2 a 27, marzo a julio de 1876. Después en libro de V y 309 páginas, bajo la siguiente portada "La holandesa en América" pro Soledad Acosta de Samper. Curazao. Imprenta la Librería de A. Berthencourt e Hijos, editores. 1889

8. "Los españoles en España”, "Gil Bayle”. España en 1390. Leyenda histórica. Publicada en el folletín "La Ley" numero 26 a 30, julio de 1876

9. "Los hidalgos de Zamora". Novela histórica y de costumbres del siglo XVI. Publicada en el folletín "El Deber" número 1 al 23, octubre a diciembre de 1878. Fechada en Bogotá, juli de 1873. Años después la autora reunió esta novela con la anterior en un solo volumen de 173 páginas y 1 de índice, editada en Bogotá, Imprenta "La Luz" en 1898

10. "Las dos reinas de Chipre" Siglo XV. Cuadros de la historia chipriota. Publicada en los tomos 1 y 2 de "La Mujer", años 1878, 79

11. "El talismán de Enrique" tomos 1 y 2 de "La Mujer", años 1878, 79

12. "Los descubridores". Cuadros históricos y novelescos. Siglo XV. "Alonso Ojeda" tomos 1, 2 y 3 años 1878, 79 de "La Mujer". En 1907 se publicó la edición separada de esta novela en Bogotá, imprenta "La Luz", tomo de 300 páginas, con la portada "los españoles en América" "Episodios históricos novelescos" "Un hidalgo conquistador" se terminó de escribir el 2 de noviembre de 1875.

13. "anales de un paseo". Novelas y cuadros de costumbres. Se empezó a publicar en los números 80 a 99 de "El Tradicionista" septiembre y octubre de 1872, más quedó inconclusa por entonces se insertó completa en los tomos 2, 3 y 4 de "La Mujer" años de 1878 a 1880.

14. "La juventud de Andrés" novela histórica y de costumbres nacionales. Fin del siglo XVIII. Publicada en "La Mujer" tomos 3 y 4 de 1880

15. "Historia de dos familias" Novela de costumbres nacionales por Olga, "La Mujer" tomo 4 de 1880

16. "La familia del tío Andrés". Época de la Independencia. Segunda parte de "La juventud de Andrés" "La Mujer" tomo 5 año de 1881 
17. "Una familia patriota". Cuadros de la época de la Independencia. Continuación de "La familia del tío Andrés". Publicados en la revista "La Familia" años de 1884 y 1885

18. "Quien busca halla". Novela de costumbres nacionales. Tiene fecha del 20 de julio de 1899, publicada como folletín de periódico bogotano en año 1903

19. "Aventuras de un español entre los indios de las Antillas" segunda novela de la serie "los españoles en América" publicada en "Lecturas para el hogar" años de 1905 y 1906

20. "Un chistoso de aldea". Cuadros de costumbres populares. Publicados en "Lecturas para el hogar" años de 1905

21. "Justicia cumplida la de Dios venida". Novela de costumbres nacionales. Publicada en el 2 tomo de "Lecturas para el hogar" años de $1906 .{ }^{22}$

\section{G- PERIODICOS}

1. "La Mujer" Revista quincenal, redactada exclusivamente por señoras y señoritas, bajo la dirección de la señora Soledad Acosta de Samper. Comenzó a publicarse el 1 de septiembre de 1878 y terminó el 15 de mayo de 1881, constituyendo una colección de cinco tomos, cada uno con 12 números de 24 páginas

2. "La Familia” Lecturas para el hogar. Revista mensual. Mayo de 1884 a diciembre de 1885. La colección de 12 números está constituida por un interesante volumen de 762 páginas de amena e instructiva lectura.

3. "El domingo de la familia cristiana" Revista semanal, bajo la dirección de la señora Soledad Acosta de Samper. Comenzó a publicarse en el mes de marzo de 1889 y terminó el 16 del mismo mes de 1890 con el número 52

4. “El Domingo". Revista semanal. Historia. Biografía. Viajes. Ciencias. Literatura. 24 números; 2 de octubre de 1898 a 10 de septiembre de 1899.380 y 562 páginas.

5. "Lecturas para el Hogar". Revista mensual, literaria, histórica e instructiva. 12 números: marzo de 1905 a marzo de 1906. 382 y 386 páginas

\section{H- TEATRO}

1. "El viajero" comedia de costumbres nacionales, en dos actos. Publicada en "La Mujer" tomo 4 año de 1880

2. "Una educación útil". Dialogo para la escuela. Publicado en "La Mujer" tomo 5 de 1880

3. "Las desdichas de Aurora" Comedia de costumbres, en cuatro actos. Publicada en el tomo 5 de "La Mujer" noviembre de 1880 a enero de 1881

4. "Las víctimas de la guerra". Drama en cinco actos y en prosa. Publicados en "La Familia" diciembre de 1884

\section{I- TRADUCCIONES}

1. Literatura danesa: "El colibrí" "El caracol y la rosa". Cuentos de Hans Cristern Andersen. "El Hogar" tomo 1 año de 1868

2. "El medicamento del alma" de Bulwer. Id., id.

3. "La ausencia" "La vida" de Bulwer. "El Hogar" tomo 2, 1869

\footnotetext{
${ }^{22}$ Según Laverde Amaya. "Biblioteca Colombiana" Bogotá 1895, la señora Acosta de Samper publicó también en un periódico de París "El eco literario" una novela francesa titulada "el esclavo de Juan Fernández" que desconozco por completo, e ignoro si sea la misma narración breve "La india de Juan Fernández" ya anotada
} 
4. "La Mujer" de Alfonso Karr. Id., id.

5. "El cordón de fuego" Episodio de la guerra de la Independencia. Traducido del francés "La América" parte literaria, tomo 1 año de 1873

6. "El verdugo" Estudios filosóficos de Balzac. "El deber". 1878.

7. "La mentira de Sabina". Novela escrita en francés por la princesa O. Cantacuzene- Altieri. "La Mujer" tomo 4 y 5 año de 1880

8. "Una expedición matinal en Tonkin", por Pierre Loti, "La Familia", diciembre de 1885

9. "La explicación del enigma" novela escrita en francés por la señora Augusta Craven. Traducida para "La Nación" por la señora Soledad Acosta de Samper. 1887. Bogotá. Imprenta de "La Luz" 336 páginas.

10. Maria Mallo M. Craick. "El rey Arturo". Versión de Soledad Acosta de Samper. Bogotá. Librería Nueva. 1894, 256 páginas

\section{J- VIAJES}

1. "Recuerdos de Suiza”. Publicados primeramente en "El Mosaico" de 1859 y 1860, edición definitiva en "La Mujer" tomo 3 páginas 109 a 283, diciembre de 1879 a mayo de 1880

2. "Costumbres y tipos europeos. Londres y París" "El Hogar" tomo 2 de 1869

3. "Hungría: Pest" publicado también en "El Hogar" y reproducido luego en el libro "Escritores colombianos" selección J. J. Borda 1873

4. "El año nuevo en París" "El Hogar" tomo 2, 1869

5. "Recuerdos de Europa". Los salones de París. La mujer en París. Los parisenses viajeros. Artículos publicados en el tomo 4 de "La Mujer" 1880

6. "De París a Nancy y Metz" "El Bien Público", número 16, 1870

7. "Peregrinaciones en Francia": la ciudad de Tours. San Martín de Tours. La tumba de San Martín. La gruta de San Martín. El santo hombre de Tours. Devoción del santo Rostro. La casa oratorio del Santo Rostro. La ciudad de Poitiers. San Hilario. Santa Radegunda. Burdeos. Pau y sus curiosidades históricas y religiosas. Lourdes. Artículos publicados en "El Domingo" años de 1898- 99

8. "Roc Amadour". "Lecturas para el hogar", número 2, abril de 1905

9. "De la ciudad de Tarbes a la de Tolosa". Clemencia Isaura. Villefranche. Artículos publicados en periódicos bogotanos.

10. "Estudios sobre Inglaterra" "Lecturas para el hogar" años de 1905- 06

11. "Viaje a España”, por Soledad Acosta de Samper. Delegada oficial de la Republica de Colombia al IX congreso Internacional de Americanistas en el Convento de la Rábida, miembros de los congresos Literario- Lutisiano- Americanos, miembro de la Academia de la Historia, de Caracas, etc. Tomo I. Bogotá. 1893. Imprenta de Antonio María Silvestre. 260 páginas. El tomo 2 fue impreso en 1894 en la Imprenta “La Luz" y contiene 269 páginas. ${ }^{23}$

\footnotetext{
${ }^{23}$ El académico Daniel Samper Ortega posee la mayor parte de las obras que se enumeran en esta bibliografía, por donación que de ellas le hizo doña Blanca Samper Acosta, hija de la ilustre escritora. Gracias a este valioso acervo he podido complementar los datos del catálogo que precede.
} 